\title{
Recent temperature variability and change in the Altiplano of Bolivia and Peru
}

\author{
J. I. López-Moreno, ${ }^{\mathrm{a}}$ E. Morán-Tejeda, ${ }^{\mathrm{a}} \mathrm{S}$. M. Vicente-Serrano, ${ }^{\mathrm{a}} \mathrm{J}$. Bazo, ${ }^{\mathrm{b}}$ C. Azorin-Molina, ${ }^{\mathrm{a}}$ \\ J. Revuelto, ${ }^{\mathrm{a}}$ A. Sánchez-Lorenzo, ${ }^{\mathrm{a}}$ F. Navarro-Serrano, ${ }^{\mathrm{c}}$ E. Aguilar ${ }^{\mathrm{d}}$ and O. Chura ${ }^{\mathrm{e}}$ \\ ${ }^{a}$ Department of Geoenvironmental Processes and Global Change, Pyrenean Institute of Ecology, CSIC, Zaragoza, Spain \\ ${ }^{\mathrm{b}}$ Department of Meteorology, Peruvian National Service of Meteorology and Hydrology (SENAMHI), Lima, Peru \\ ${ }^{c}$ Department of Physical Geography and Regional Geographic Analysis, University of Sevilla, Spain \\ d The Centre for Climate Change (C3), Rovira i Virgili University, Tarragona, Spain \\ e Department of Meteorology, Bolivian National Service of Meteorology and Hydrology (SENAMHI), La Paz, Bolivia
}

\begin{abstract}
This work analysed the changes in air temperature in 25 meteorological stations in the Altiplano and the surrounding Andean slopes of Bolivia and Peru, and their relationship with El Niño-Southern Oscillation (SO) and the Pacific Decadal Oscillation (PDO). The analysis focused on annual, warm season (DJF) and cold season (JJA) maximum and minimum temperatures. All analyses were undertaken during 1965-2012, but some analyses were also from 1945 and 1955 when data were available. Principal component analysis was applied to the annual and seasonal series to identify spatial differences of changes in maximum and minimum air temperature. There was an overall increase of temperatures since the mid-20th century. The most intense and spatially coherent warming was observed for annual and warm season maximum temperature, with warming rates from 0.15 to $0.25^{\circ} \mathrm{C} \mathrm{decade}{ }^{-1}$. Changes in the cold season maximum temperature were more heterogeneous, and statistically significant trends were mostly in the Bolivian Altiplano. Minimum temperatures increased, but there was higher spatial variability and lower rates of warming. Maximum temperature was negatively correlated with the Southern Oscillation index ( $\mathrm{SO}$ ) in the warm season, and positively correlated with the SO in the cold season; there were less statistically significant correlations with the PDO, that exhibited inverse sign than those for SO. The strongest correlations were in the region near Lake Titicaca. The negative correlation of minimum temperatures with SO and the positive correlation of minimum temperatures with PDO were lower than the observed for maximum temperature. The changes in temperature and correlations with SO and PDO were highly dependent on the selected period, with stronger trends in the last 30-40 years. This suggests reinforcement of warming rates that cannot be only explained by SO and PDO variability.
\end{abstract}

KEY wORDS Altiplano; Andes; Bolivia; Peru; air temperature; trends; Southern Oscillation; Pacific Decadal Oscillation

Received 11 December 2014; Revised 26 June 2015; Accepted 29 June 2015

\section{Introduction}

Recent research indicates that projected climate warming will severely impact the tropical Andes and the local population (Vuille et al., 2008). The estimated rate of warming in this region since the second half of the 20th century is $0.11-0.15^{\circ} \mathrm{C}_{\text {decade }}{ }^{-1}$ (Vuille et al., 2008; Bradley et al. 2009; Gallaire et al., 2010), and this warming is superimposed upon a strong decadal variability (Vuille et al., 2003; Rabatel et al., 2013; Seiler et al., 2013a). Thus, warming in the tropical Andes clearly exceeds the global warming rate, estimated as $0.06^{\circ} \mathrm{C}$ decade ${ }^{-1}$ (Bradley et al., 2006). Climate models project a much more intense warming in the tropical Andes, with a warming rate of $4-5^{\circ} \mathrm{C}$ by the end of the 21st century (Bradley et al., 2006; Urrutia and Vuille, 2009; Seiler et al., 2013b). Many people live in the tropical Andes (Magrin et al., 2007), and these people will

\footnotetext{
* Correspondence to: J. I. López-Moreno, Department of Geoenvironmental Processes and Global Change, Pyrenean Institute of Ecology, CSIC, Avda Montañana 1005, Zaragoza 50080, Spain. E-mail: nlopez@ipe.csic.es
}

be greatly affected by climate change (Vergara et al., 2007; Rangecroft et al., 2013).

The highlands of Bolivia and Peru (Altiplano and Andean slopes) provide an example of how air temperatures impact local populations. This region has some of the most elevated agriculture lands in the world (Thibeault et al., 2010; Rangecroft et al., 2013), often higher than $4000 \mathrm{~m}$ a.s.l. Sixty percentage of these agricultural lands rely solely on rainfall for water, and most of these lands may be considered subsistence agriculture (García et al., 2007). Although warmer temperatures are often associated with improved conditions for agriculture, because of the longer growth periods and lower frequency of frosts, this can also cause increased water deficit because of the high atmospheric evaporative demand (AED) (García et al., 2004). Given the intense aridity of the tropical Andes, in which precipitation is largely exceeded by AED (Battisti and Naylor, 2009; Thibeault et al., 2010), the negative impact of an increased AED outweighs the potential benefits of warming. In addition, increasing heat stress and drought may lead to an increase of insect pests (Garret et al., 2006). 
The air temperature increase in this region that occurred since 1920-1930 is considered one of the main drivers of the accelerated glacier retreat. Bolivia has $20 \%$ and Peru has $71 \%$ of all tropical glaciers in the world, but their sizes have declined dramatically in recent decades (Gallaire et al., 2010; Rabatel et al., 2013; Rangecroft et al., 2013; López-Moreno et al., 2014). Bradley et al. (2009) estimated that the increased elevation of the regional frost height was $10-20 \mathrm{~m} \mathrm{decade}^{-1}$. Most glaciers of the Cordillera Real (Bolivia) and southern Peru are small or medium in size (Francou et al., 2003), and these glaciers are most vulnerable to shrinkage in the short and medium term (Rabatel et al., 2013). The glacier retreat in this region is a major concern because glacier water is needed for agriculture and domestic use, and it is often the only water source during the dry (May to September) season (Vergara et al., 2007).

Thus, there is a need for investigating the magnitude of warming and to identify and better understand the mechanisms of air temperature variability in this region. In addition to previous studies at wide regional scales (Vuille and Bradley, 2000; Vuille et al., 2008; Bradley et al., 2009), there are long and high-quality air temperature series for Bolivia and Peru that allow more focused studies of temperature change and its relationship with different atmospheric circulation processes governed by El Niño Southern Oscillation (ENSO, characterized in this study through the SO index), the Pacific Decadal Oscillation (PDO) and the Arctic Oscillation (AO) (Lavado-Casimiro et al., 2013; Seiler et al., 2013a). Previous research stressed the different behaviours of the lowlands and highlands of Bolivia and Peru, and determined that the annual temperature increase was about $0.1^{\circ} \mathrm{C}$ since 1960 . These studies also stressed that temperature change had a clear decadal variability that was strongly related to ENSO, PDO and AO. Therefore, selection of different study periods might yield different results regarding the reported warming trend. It is also well known that the relationship between climate records and atmospheric indices is not stationary, and that there is large variability between periods and regions (e.g. Vicente-Serrano and López-Moreno, 2008). Specifically, the nature of the warming trend may depend on the period being analysed.

This study focused on the high elevation regions of Bolivia (Altiplano and Andean slopes) and the Peruvian Altiplano to identify trends in the spatial patterns and interannual variability of annual, cold season (JJA) and warm season (DJF) maximum and minimum temperature series, and the influence of SO and PDO. This work used the most complete collection of temperature records available to date for this area, from 1945 to 2012, and examined the impact of using different study periods on the results.

\section{Study area}

The study area is a longitudinal band along the Andes and its foothills and the Altiplano (high plains at $\sim 3800 \mathrm{~m}$ a.s.l.) in northern Bolivia and southern Peru (Figure 1). The elevation of the meteorological stations ranges from 1875 to $4320 \mathrm{~m}$ a.s.l. (Table 1). The study area is in the tropical zone, and the climate is dominated by some prevailing patterns of global circulation, such as the trade winds and the ENSO (Mendoza et al., 2007). However, the presence of the Andes leads to strong local and regional differences in climate, and there are gradients of temperature and precipitation according to elevation. Thus, the annual precipitation is about $2000 \mathrm{~mm}$ in the

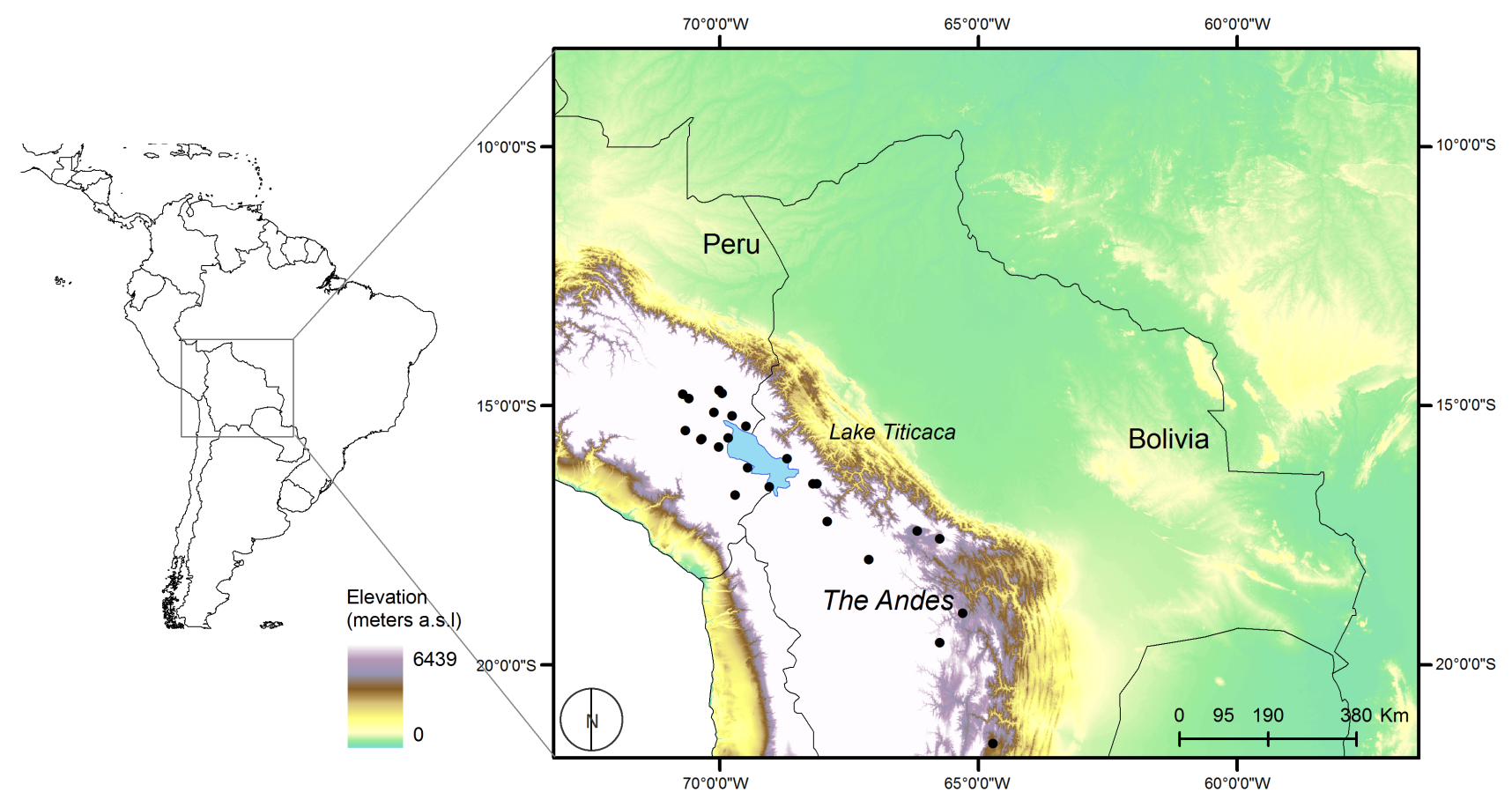

Figure 1. Study area and location of the 25 meteorological stations. 
Table 1. Meteorological stations that provided data for this study.

\begin{tabular}{|c|c|c|c|c|c|}
\hline Code & Name & Country & Elevation (m a.s.1.) & Latitude $\left({ }^{\circ}\right)$ & Longitude $\left({ }^{\circ}\right)$ \\
\hline 1 & Tarija & Bolivia & 1875 & -20.47 & -63.28 \\
\hline 2 & Sucre & Bolivia & 2904 & -18.99 & -64.7 \\
\hline 3 & Patacamaya & Bolivia & 3793 & -16.76 & -66.08 \\
\hline 4 & Oruro & Bolivia & 3702 & -16.03 & -66.88 \\
\hline 5 & Potosi Los Pinos & Bolivia & 3950 & -18.42 & -64.25 \\
\hline 6 & Central La Paz & Bolivia & 3632 & -15.49 & -67.88 \\
\hline 7 & El Alto Aeropuerto & Bolivia & 4071 & -15.49 & -67.8 \\
\hline 8 & Cochabamna & Bolivia & 2548 & -16.58 & -65.82 \\
\hline 9 & Arani & Bolivia & 2767 & -16.43 & -64.25 \\
\hline 10 & Belen & Bolivia & 3833 & -15.98 & -67.3 \\
\hline 11 & Capachica & Peru & 3819 & -14.38 & -68.16 \\
\hline 12 & Juli & Peru & 3825 & -15.8 & -68.54 \\
\hline 13 & Puno & Peru & 3840 & -14.18 & -69.98 \\
\hline 14 & Huancane & Peru & 3860 & -14.8 & -68.24 \\
\hline 15 & Desagüadero & Peru & 3860 & -15.43 & -68.96 \\
\hline 16 & Cabanillas & Peru & 3890 & -14.36 & -69.65 \\
\hline 17 & Huaraya_Moho & Peru & 3890 & -14.61 & -68.51 \\
\hline 18 & Lampa & Peru & 3900 & -14.64 & -69.63 \\
\hline 19 & Progreso & Peru & 3905 & -13.31 & -69.64 \\
\hline 20 & Chuquibambilla & Peru & 3910 & -13.2 & -69.27 \\
\hline 21 & Ayaviri & Peru & 3920 & -13.12 & -69.41 \\
\hline 22 & Arapa & Peru & 3920 & -14.86 & -69.88 \\
\hline 23 & Mazo_Cruz & Peru & 3970 & -15.25 & -68.29 \\
\hline 24 & Muñani & Peru & 4119 & -13.22 & -68.03 \\
\hline 25 & Pampahuta & Peru & 4320 & -14.51 & -69.32 \\
\hline
\end{tabular}

Andes, and is about $1200 \mathrm{~mm}$ towards the foothills and Altiplano region (eastwards). Precipitation mainly occurs from November to March. The climate in the Andean peaks is considered 'polar', with temperatures below $0{ }^{\circ} \mathrm{C}$ during most of the year, leading to the formation and consolidation of glaciers. In the Altiplano, temperatures fluctuate between a night-time minimum (below $-5^{\circ} \mathrm{C}$ ) and a day-time maximum (sometimes around $25^{\circ} \mathrm{C}$ ). Although there is little seasonal variations of temperature, a cold season (JJA) and a warm season (DJF) can be differentiated, especially with regard to minimum temperatures, with differences that exceed $7^{\circ} \mathrm{C}$ between seasons.

\section{Data and methods}

Monthly air temperature data from 25 meteorological stations managed by the National Weather Services (SENAMHI, Servicio Nacional de Meteorología e Hidrología) of Bolivia and Peru were used. Most of the stations are located in the airports of the respective locations and hence far from the city centres and in flat areas. We only used data from stations that had records from January 1965 to December 2013 and had less than $10 \%$ missing data. We considered hydrological years to start in October (beginning of the wet season) and end in September of the next year (end of the dry season). Hence the study period ended in the hydrological year 2012 (September 2013). Figure 1 shows the locations of the meteorological stations, and Table 1 lists the names, coordinates and elevations for each station.

All the time series were subjected to quality control and homogenization. The quality control procedure compared the rank of each data record with the average rank of the data recorded at adjacent stations. The maximum allowed difference between a candidate observation and the average values of the percentiles in the four closest neighbouring observatories was set at 60 percentile units. If the difference was higher than this the candidate observation was considered questionable and removed from the data set (Vicente-Serrano et al., 2010). Homogeneity was tested using the recently developed relative method (HOMER-HOMogenization software in R), which compares each candidate series with the number of available series (Mestre et al., 2013). HOMER is a semi-automatic methodology that combines automatic joint segmentation with a pairwise comparison to the closest station to each candidate station. In this way, values flagged by the automated quality control process where manually checked with climatological criteria. According to these criteria, we corrected or validated the candidate series. The segmentation analysis was based on annual and seasonal data, and used differences in temperature for comparisons. This method provides an estimation of break points in time series relative to neighbouring stations, and indicates high probabilities of inhomogeneities. Located breaks can then only be caused by one of the two stations involved in the comparison. By repeating this comparison many times, varying the reference series, breaks appearing repeatedly and with the same sign are attributed to the candidate series. The joint detection approach, used to confirm the breaks allocated after the pairwise detection, is based on a multivariate statistical modelling approach. All the series are considered at the same time and a model with the optimal number and location of breakpoints (using a penalty 
Chuquibambilla vs. Progreso
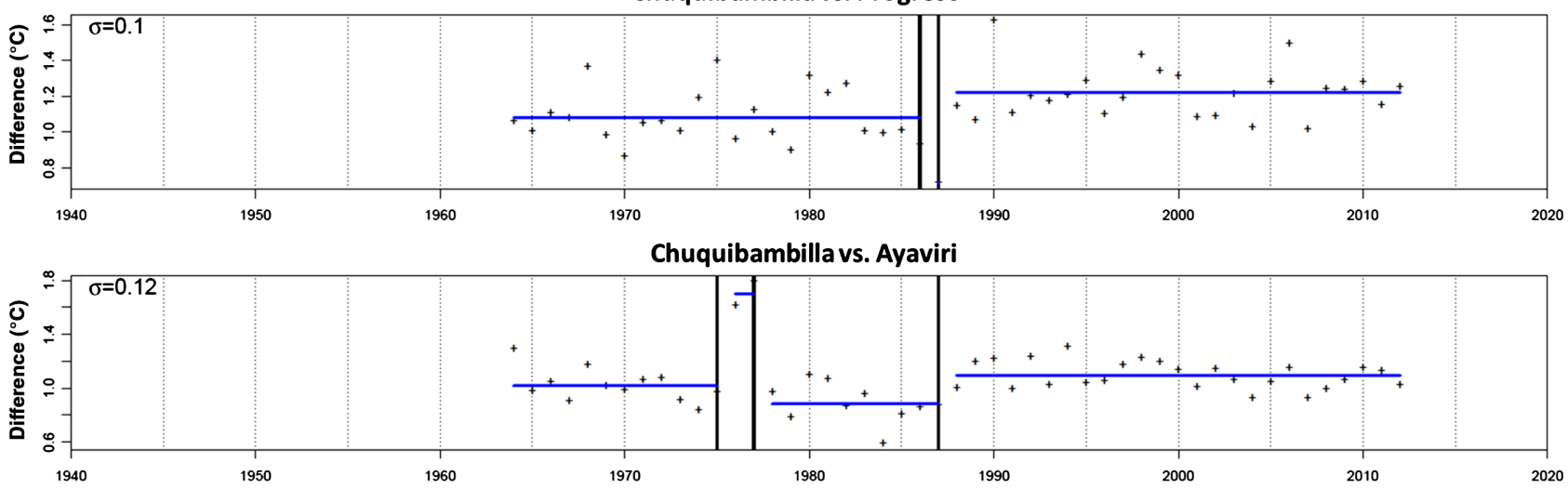

Chuquibambillavs. Arapa

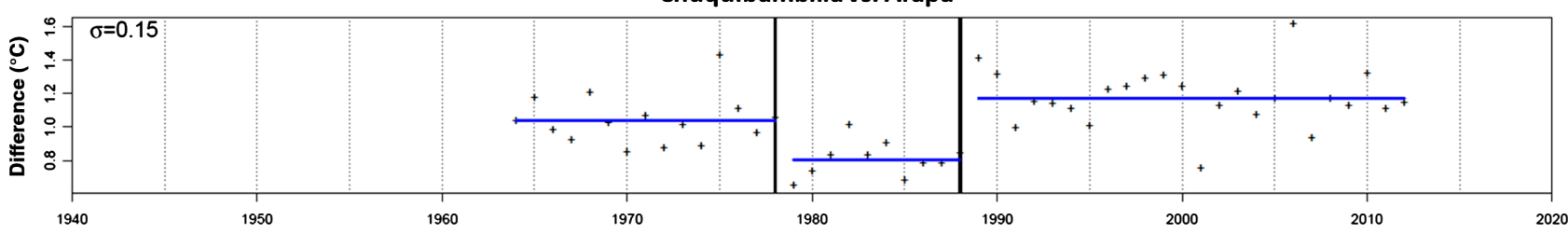

Chuquibambilla vs. Desaguadero

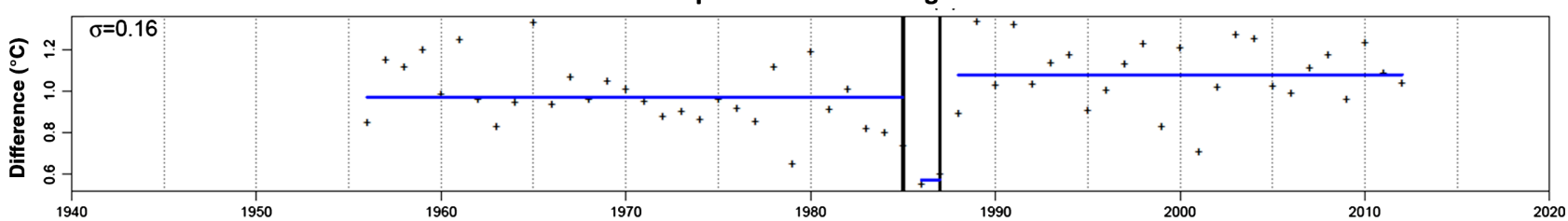

Figure 2. Application of HOMER homogeneity procedure to the observatory of Chuquibambilla using HOMER.

factor to penalize the introduction of new breakpoints) by means of dynamic programming (see Mestre et al., 2013 and Picard et al., 2011). Figure 2 shows an example of the segmentation approach followed by HOMER, in which a pairwise comparison of annual maximum temperature series in the observatory of Chuquibambilla is compared with the annual series of neighbour stations (Progreso, Ayaviri, Arapa and Desaguadero). The differences between annual temperature series are computed each year and the segmentation analysis allows identifying breakpoints in the series of differences. If the breakpoint is identified between the candidate observatory and a number of neighbour observatories (as observed in 1987 in Chuquibambilla), a temporal inhomogeneity is identified. This approach was applied to each of the available $T_{\max }$ and $T_{\min }$ series. We found inhomogeneities in 18 maximum temperature and 22 minimum temperature series, with a total of 34 and 42 inhomogeneities, respectively. The maximum number of inhomogeneities found in an observatory was five. HOMER corrected the inhomogeneities and completed missing values based on the methodology proposed by Mestre et al. (2013), in which monthly coefficients are obtained between the periods before and after each inhomogeneity and applied to the monthly series. The application of the homogeneity test ensures that reported changes in temperature cannot be associated to instrumental changes or urbanization processes.
Temporal trends of $T_{\max }$ and $T_{\min }$ were computed with the pre-whitening procedure described by Yue and Wang (2002), which uses the Mann-Kendall test to determine the significance of trend, and the Thiel-Sen estimator to determine the linear slope of the trend. These tests are non-parametric and widely used to determine monotonic trends in data series regardless of their statistical distributions (valid for series that do not follow a Gaussian distribution). Trends were calculated for the annual values, cold season values (JJA) and warm season values (DJF), to facilitate comparison with the results of previous research in the region (Vuille et al., 2008; Seiler et al., 2013a). The period of 1965-2012 was analysed, but trends and correlations with SO and PDO were also computed for longer periods (1945-2012 and 1955-2012) in stations where data were available. This allowed determination of the rate of temperature change as a function of the study period. A $p$ value less than 0.05 was considered the threshold for a statistically significant trend.

We also calculated break points (i.e. dates when there was a significant change in the strength of the linear relationship), which indicate structural changes in the temperature-time linear regression. This calculation employed the breakpoint $\mathrm{R}$ function (strucchange package; see Zeileis et al., 2003 for details) and is based on the assumption that in a linear regression:

$$
y_{i}=x_{i^{\prime}} b+c_{i}
$$


There are $m$ breakpoints, where the coefficients shift from one stable regression relationship to a different one. Thus, there are $m+1$ segments in which the regression coefficients are constant, and the model can be expressed as:

$$
y_{i}=x_{i^{\prime}} b_{j}+c_{i}\left(i=i_{\{j-1\}+1}, \ldots, i_{j}, j=1, \ldots, m+1\right)
$$

where $j$ denotes the segment index. Break points are estimated by minimizing the residual sums of squares (RSS) of Equation (2), with the dates of the breaks as variables. Bai (1997) provided the foundations of this method, and Bai and Perron (2003) described the full algorithm.

The three series of $T_{\max }$ and $T_{\min }$ (annual, DJF and JJA) were subjected to principal component analysis (PCA) to identify homogeneous groups of meteorological stations in terms of air temperature. PCA summarizes the total variance of a large number of correlated variables as a small number of uncorrelated variables and has been widely used in climatological studies (e.g. Richman, 1986; Huth, 2006). The resulting uncorrelated variables are called principal components (PCs) and consist of linear combinations of the original variables. The application of PCA to the air temperature series was performed in S mode to obtain general temporal patterns. A correlation matrix was selected for the analysis because it provides a more efficient representation of the variance in the data set. The criterion of component selection was accorded an eigenvalue $>1$ (Hair et al., 1998). Afterwards, components were rotated (Varimax) to redistribute the final explained variance and to obtain more stable, physically robust patterns (Richman, 1986). Stations that had correlation coefficients greater than 0.65 with the PCs were identified as representatives of the temporal series by the $\mathrm{PC}$; the station that had a higher correlation with the corresponding PC (normally $r>0.9$ ) was used to illustrate the different patterns of temporal evolution of the $T_{\max }$ and $T_{\min }$ series. For these representative stations, the temporal series (and the trend line for the period 1965-2012) and moving windows trends through heat-map plots are presented to show how the magnitude and significance of the changes differ as a function of the selected start and end dates, with a minimum period length of 30 years.

We also examined the relationships of the temperature series with the Southern Oscillation index (SO, Climate Research Unit, http://www.cru.uea.ac.uk/cru/data/soi/) that responds tightly to changes in the ocean temperatures across the Eastern Pacific and it is highly correlated with El Niño 3.4 and the PDO (Joint Institute for the study of the Atmosphere and Ocean, http://jisao.washington.edu/pdo/PDO.latest) that has been often described as a long-lived El Niño-like pattern of Pacific climate variability (Zhang et al., 1997). The ENSO and PDO were identified as major drivers of decadal variability in air temperature over the study region (Seiler et al., 2013a). We have also used both indices in this study aiming to facilitate the comparison of our results with previous research in the region. Correlations between SO and PDO and temperature were computed using the detrended series of $T_{\max }$ and $T_{\min }$ (by removing their linear trends) in order to remove the noise of the possible temperature trends during the study period on the significance and strength of the relationships. An initial exploratory analysis identified the seasonal level (monthly aggregates of 3, 6 and 12 months) that had the best correlation between these two atmospheric circulation indices and the annual, DJF and JJA temperatures (Vicente-Serrano et al., 2011). This analysis indicated that the previous 6-month averages for SO and PDO best correlated with $T_{\max }$ and $T_{\min }$ for the warm (DJF) and cold (JJA) seasons. Thus, the temperatures of DJF were correlated with average SO and PDO values from September to February, and temperatures of JJA were correlated with the average SO and PDO values from March to August. The correlation of these two indices was in the opposite direction with the temperatures of DJF and JJA (i.e. September to February SO correlated negatively with DJF temperatures; March to August SO correlated positively with JJA temperatures; see Section 4). Thus, the correlation between annual temperature and annual SO and PDO values is null, and not presented. In addition to the analysis of correlations for the period 1965-2012, we also examined when possible correlations of other periods (1945-2012 and 1955-2012), and presented heat-map plots showing correlations between SO, PDO and temperature.

\section{Results}

\subsection{Changes in air temperature}

Figure 3 shows the spatial distribution of trends across the study area for $T_{\max }$ and $T_{\min }$ from 1965 to 2012, and Table 2 shows the details of the decadal changes for this period and for the periods of 1945-2012 and 1955-2012 in stations where data were available.

Analysis of the $T_{\max }$ data indicated that annual $T_{\max }$ increased at most stations, and this increase was statistically significant in 22 of 25 stations (Figure 2, top). The overall rate of $T_{\max }$ increase was $0.08-0.41^{\circ} \mathrm{C}$ decade $^{-1}$ in the study region. In sites where longer temperature records were available, there were also statistically significant increases in $T_{\text {max }}$, but the overall rate of change was not as great. During the warm season (DJF), 18 of 25 stations had statistically significant increases of $T_{\max }$, and there were larger differences in the rate of warming, with several stations exceeding $0.25^{\circ} \mathrm{C}$ decade $^{-1}$ and others with rates below $0.10^{\circ} \mathrm{C}$ decade $^{-1}$. During the cold season (JJA), 18 of 25 stations had significant increases in $T_{\max }$, and there were also large differences in the rate of increase among stations, with some increases in the Bolivian Altiplano exceeding $0.3^{\circ} \mathrm{C}$ decade $^{-1}$. In both seasons, the increases of $T_{\text {max }}$ were slightly lower when longer records were analysed. Analysis of the change in $T_{\text {max }}$ over time indicated that most stations had 'break points', i.e. significant changes in the slope of the linear trend (Table 2, top). In the case of annual values, and cold season (JJA) values, there were breaks in the $T_{\max }$ in the late 1990s and 


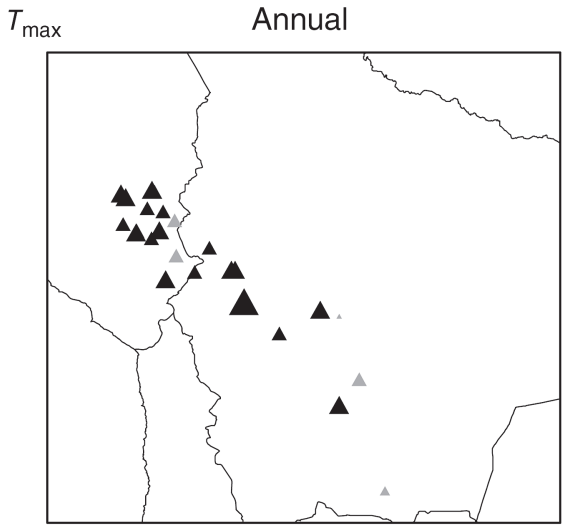

$T_{\min }$

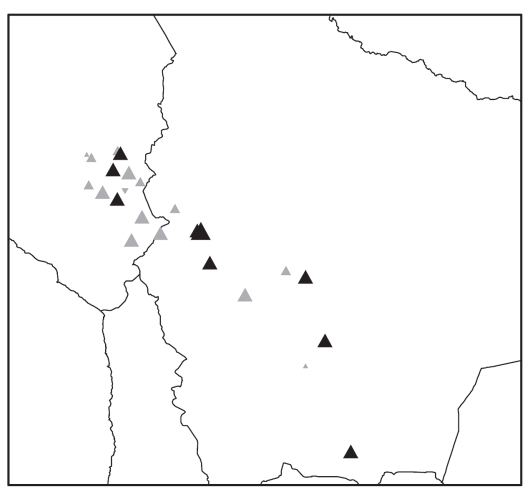

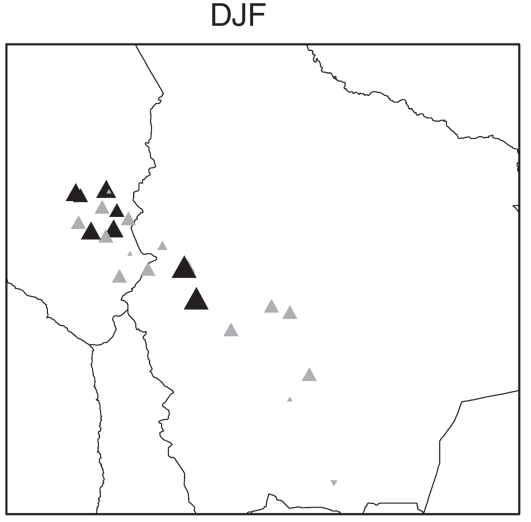

$\triangle \triangle \triangle \triangle \Delta$

$\begin{array}{llllll}0.5 & 0.4 & 0.3 & 0.2 & 0.1 & { }^{\circ} \mathrm{C} \text { decade }^{-1}\end{array}$

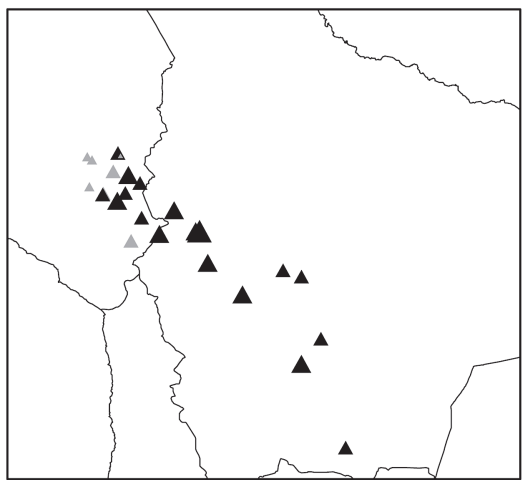

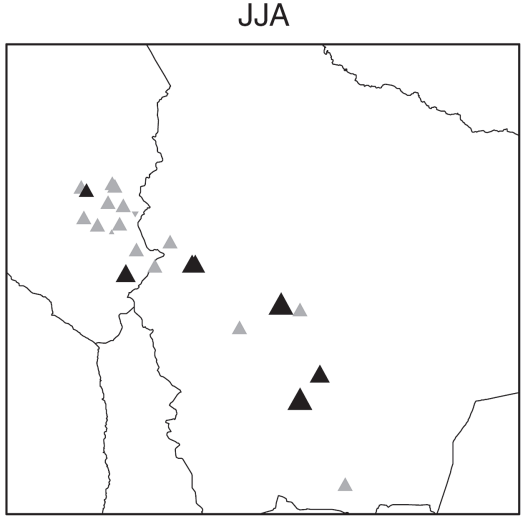

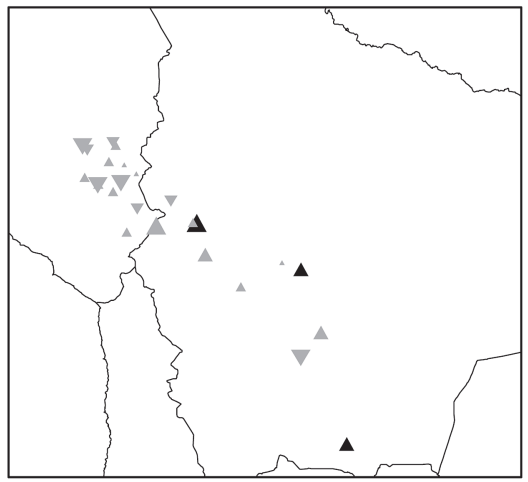

Figure 3. Spatial distribution of changes in $T_{\max }$ and $T_{\min }$ for 1965-2012. Upward-facing triangle ( $\Delta$ ): positive trend; downward facing triangle ( $\left.\nabla\right)$ : negative trend; black triangle: statistically significant trend $(p<0.05)$.

early 2000s. Fewer stations had $T_{\max }$ break points for the warm season (DJF), but these break points occurred at several sites during the second half of the 1970s, and in two other stations in 1986.

Analysis of the $T_{\min }$ data also indicated positive trends at most stations from 1965 to 2012, but the warming rates were generally lower and the increases were only significant in 13 of 25 stations (Figure 2, bottom). The increases of $T_{\min }$ were more marked during the warm season (DJF), with statistically significant increases at 24 of 25 stations, many of them exceeding $0.2^{\circ} \mathrm{C}$ decade $^{-1}$. The cold season had much lower rates of warming, with statistical significance at only six stations; and three stations even had statistically significant decreases in $T_{\min }$ during this period. The use of earlier starting dates (1945 or 1955) from available meteorological stations yielded results similar to the reported results, although warming rates were smaller in these longer time series. Most of the $T_{\min }$ series had break points during the warm season (Table 2, bottom). Breaks occurred at ten sites in the 1990s, six sites in the 1970s, three sites in the 1980s, and one site in the 2000s. There were fewer break points in the annual series (ten stations, mostly in the 1970s and 1990s) and during the cold season (five stations, mostly in the 1960s and 2000s).

\subsection{Principal component analysis}

Table 3 shows the results of the PCA. For the analysis of annual and DJF $T_{\max }$, one PC accounted for more than
$70 \%$ of total variance. This means that temporal evolution of annual and DJF. $T_{\max }$ had low spatial variability in the study region. On the contrary, the evolution of JJA $T_{\max }$ had greater spatial diversity, and three PCs accounted for most of the variance $(30.7,24.9$ and $15.8 \%)$. The PCA of $T_{\min }$ had much more spatial heterogeneity, and four PCs accounted for most of the variance in the annual, DJF and JJA series. Table 3 also shows the correlation between each PC and each station, with values highlighted when the loading (Pearson's $r$ ) was above 0.65 .

Figure 4 shows the distribution of stations with correlation coefficients above 0.65 in the PCA of annual $T_{\max }$. The most correlated station (circled station in left panel), the corresponding temporal evolution and heat-map (right panel) show the magnitude of change $\left({ }^{\circ} \mathrm{C}_{\text {year }}{ }^{-1}\right)$ for different 30-year periods. The inset dots inform about the statistical significance of these trends. These results show that the increase of annual $T_{\max }$ was affected by interannual and decadal variability superimposed upon a long-term increase in annual $T_{\max }$. The heat map indicates the greatest warming trends that occurred after the mid-1960s.

Figures 5 and 6 are the corresponding plots for $T_{\max }$ during the warm (DJF) and the cold season (JJA), respectively. The $T_{\max }$ increase during the warm season was weaker than the increase of annual $T_{\max }$, and the greatest rate for the warm season $T_{\max }$ was the most recent 30-year period (since the 1980s). For the cold season (JJA), the three PCs had significant positive trends for the 1965-2012 period, 
Table 2. Decadal changes in $T_{\max }$ (top) and $T_{\min }$ (bottom) for different time periods and break points in these time series for the 25 stations.

\begin{tabular}{|c|c|c|c|c|c|c|c|c|c|c|c|c|}
\hline \multirow[t]{2}{*}{ Station } & \multicolumn{4}{|c|}{ Annual } & \multicolumn{4}{|c|}{ DJF } & \multicolumn{4}{|c|}{ JJA } \\
\hline & 1945 & 1955 & 1965 & Break point & 1945 & 1955 & 1965 & Break point & 1945 & 1955 & 1965 & Break point \\
\hline Tarija & & & 0.10 & & & & -0.04 & & & & 0.17 & \\
\hline Sucre & & 0.14 & 0.18 & 1994 & & 0.13 & 0.11 & & & 0.22 & 0.23 & 1995 \\
\hline Patacamaya & & 0.24 & 0.41 & 2002 & & 0.19 & 0.32 & & & 0.37 & 0.51 & 2003 \\
\hline Oruro & 0.13 & 0.17 & 0.19 & 2006 & 0.07 & 0.10 & 0.20 & & 0.16 & 0.24 & 0.16 & 2005 \\
\hline Potosi Los Pinos & 0.12 & 0.18 & 0.24 & 1993 & 0.06 & 0.11 & 0.04 & & 0.28 & 0.22 & 0.38 & 1993 \\
\hline Central La Paz & & 0.16 & 0.23 & 1997 & & 0.11 & 0.15 & & & 0.16 & 0.26 & 1979 \\
\hline El Alto Aeropuerto & & & 0.28 & 1997 & & & 0.33 & 1976 & & & 0.30 & 1994 \\
\hline $\begin{array}{l}\text { Cochabamna } \\
\text { Arani }\end{array}$ & & 0.18 & $\begin{array}{l}\mathbf{0 . 2 1} \\
0.08\end{array}$ & 1997 & & 0.17 & $\begin{array}{l}0.12 \\
0.18\end{array}$ & & & 0.26 & $\begin{array}{l}0.32 \\
0.20\end{array}$ & $\begin{array}{l}1995 \\
1983\end{array}$ \\
\hline$\leftrightarrows$ Belen & & 0.15 & 0.17 & 2004 & & 0.10 & 0.10 & 1976 & & 0.13 & 0.16 & 2005 \\
\hline Е્ત Capachica & & & 0.23 & 2003 & & & 0.24 & 1979 & & & 0.17 & 1976 \\
\hline Juli & & & 0.10 & & & & 0.03 & & & & 0.16 & \\
\hline 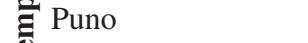 & & & 0.16 & 1997 & & & 0.13 & & & & 0.09 & 2005 \\
\hline ฮ Huancane & & & 0.18 & 2004 & & & 0.16 & & & & 0.15 & 2005 \\
\hline E Desagüadero & & & 0.18 & & & & 0.15 & & & & 0.11 & \\
\hline I Cabanillas & & & 0.18 & 2004 & & & 0.09 & & & & 0.11 & 2005 \\
\hline Huaraya_Moho & & & 0.10 & 1983 & & & 0.15 & & & & -0.02 & 1984 \\
\hline$\sum$ Lampa & & & 0.21 & 2006 & & & 0.25 & 1986 & & & 0.07 & 2005 \\
\hline Progreso & & & 0.22 & 1997 & & & 0.20 & & & & 0.18 & 2005 \\
\hline Chuquibambilla & & 0.12 & 0.25 & 2004 & & 0.18 & 0.29 & 1986 & & 0.05 & 0.17 & 2005 \\
\hline Ayaviri & & & 0.23 & 1994 & & & 0.17 & & & & 0.20 & 2005 \\
\hline Arapa & & & 0.19 & 1997 & & & 0.10 & & & & 0.16 & 2006 \\
\hline Mazo_Cruz & & & 0.23 & 2006 & & & 0.17 & & & & 0.27 & 2006 \\
\hline Muñani & & & 0.15 & 2004 & & & 0.04 & & & & 0.11 & 2005 \\
\hline Pampahuta & & & 0.20 & 2006 & & & 0.16 & & & & 0.17 & \\
\hline Tarija & & & 0.11 & & & & 0.20 & 1982 & & & 0.11 & \\
\hline Sucre & & & 0.11 & 1976 & & & 0.15 & 1976 & & & 0.13 & 1976 \\
\hline Patacamaya & 0.05 & 0.07 & 0.15 & 1998 & 0.14 & 0.19 & 0.25 & 2002 & 0.01 & 0.06 & 0.14 & \\
\hline Oruro & -0.10 & 0.07 & 0.11 & 1972 & -0.10 & 1.16 & 0.21 & 1993 & -0.15 & 0.11 & 0.03 & \\
\hline Potosi Los Pinos & 0.08 & 0.11 & 0.02 & & 0.20 & 0.22 & 0.20 & 1996 & 0.03 & 0.09 & -0.10 & 1978 \\
\hline Central La Paz & & 0.26 & 0.27 & 1982 & & 0.32 & 0.38 & 1979 & & 0.22 & 0.21 & 1986 \\
\hline El Alto Aeropuerto & & & 0.14 & & & & 0.21 & 1993 & & & 0.03 & \\
\hline Cochabamna & & 0.07 & 0.09 & 1972 & & 0.14 & 0.16 & 1972 & & 0.04 & 0.02 & \\
\hline Arani & & & 0.19 & 1993 & & & 0.17 & 1993 & & & 0.18 & \\
\hline Belen & & -0.02 & 0.06 & & & 0.12 & 0.21 & 1996 & & -0.06 & -0.06 & 2004 \\
\hline ¿ Capachica & & & -0.02 & & & & 0.17 & 1983 & & & -0.13 & \\
\hline$\Xi$ Juli & & & 0.11 & & & & 0.17 & 1996 & & & -0.02 & \\
\hline (7) Puno & & & 0.17 & 1998 & & & 0.24 & 1997 & & & 0.08 & \\
\hline 气̈ Huancane & & & 0.10 & & & & 0.29 & 1978 & & & 0.02 & \\
\hline Е્ฮ Desagüadero & & & 0.12 & 1972 & & & 0.20 & 1974 & & & 0.22 & 1972 \\
\hline ‡ Cabanillas & & & 0.10 & 1997 & & & 0.13 & 1997 & & & 0.06 & \\
\hline छ Huaraya_Moho & & & 0.08 & 1981 & & & 0.19 & 1997 & & & 0.00 & \\
\hline Lampa & & & 0.04 & & & & 0.17 & 1993 & & & -0.19 & \\
\hline$\stackrel{\bar{\Xi}}{\bar{\tau}}$ Progreso & & & 0.05 & & & & 0.17 & & & & -0.09 & \\
\hline$\sum$ Chuquibambilla & & 0.05 & 0.04 & & & 0.08 & 0.11 & & & 0.03 & -0.14 & \\
\hline Ayaviri & & & 0.06 & & & & 0.12 & 1981 & & & -0.03 & \\
\hline Arapa & & & 0.12 & & & & 0.16 & 1974 & & & 0.09 & \\
\hline Mazo_Cruz & & & 0.13 & & & & 0.15 & & & & 0.08 & \\
\hline Muñani & & & 0.12 & & & & 0.10 & & & & 0.09 & \\
\hline Pampahuta & & & 0.06 & & & & 0.11 & & & & 0.05 & \\
\hline
\end{tabular}

Bold numbers indicate significant trends $(\alpha<0.05)$.

but there were clear differences in interannual evolution. PC1 represents most of the Peruvian stations, and PC2 represents most of the Bolivian stations located around Lake Titicaca and some sites in the Altiplano. No stations had significant changes for any of the tested 30-year periods. PC3 represents Bolivian stations in the Andean slopes. This also had an increase during the study period and, in contrast to $\mathrm{PC} 1$ and $\mathrm{PC} 2$, had significant changes for many study periods (note the many black dots in the heat map in the bottom right of Figure 5). The highest rate of warming was for the period after 1960 .

Figures 7-9 are the corresponding plots for $T_{\min }$. In general, these plots show greater spatial variability of $T_{\text {min }}$ than $T_{\max }$ and no clear geographic patterns in the spatial distributions. Stations highly correlated with each component appear to be spread over the study area, and many 


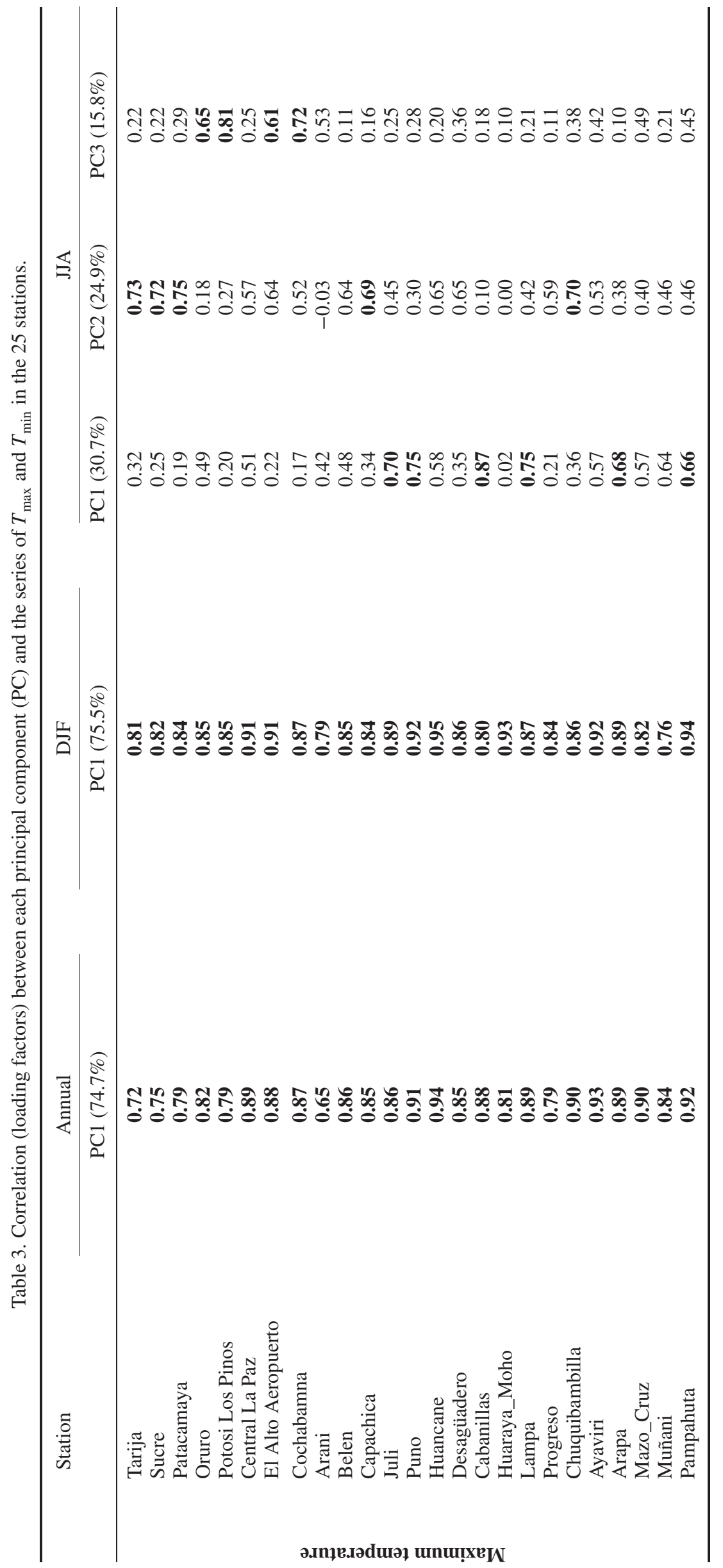




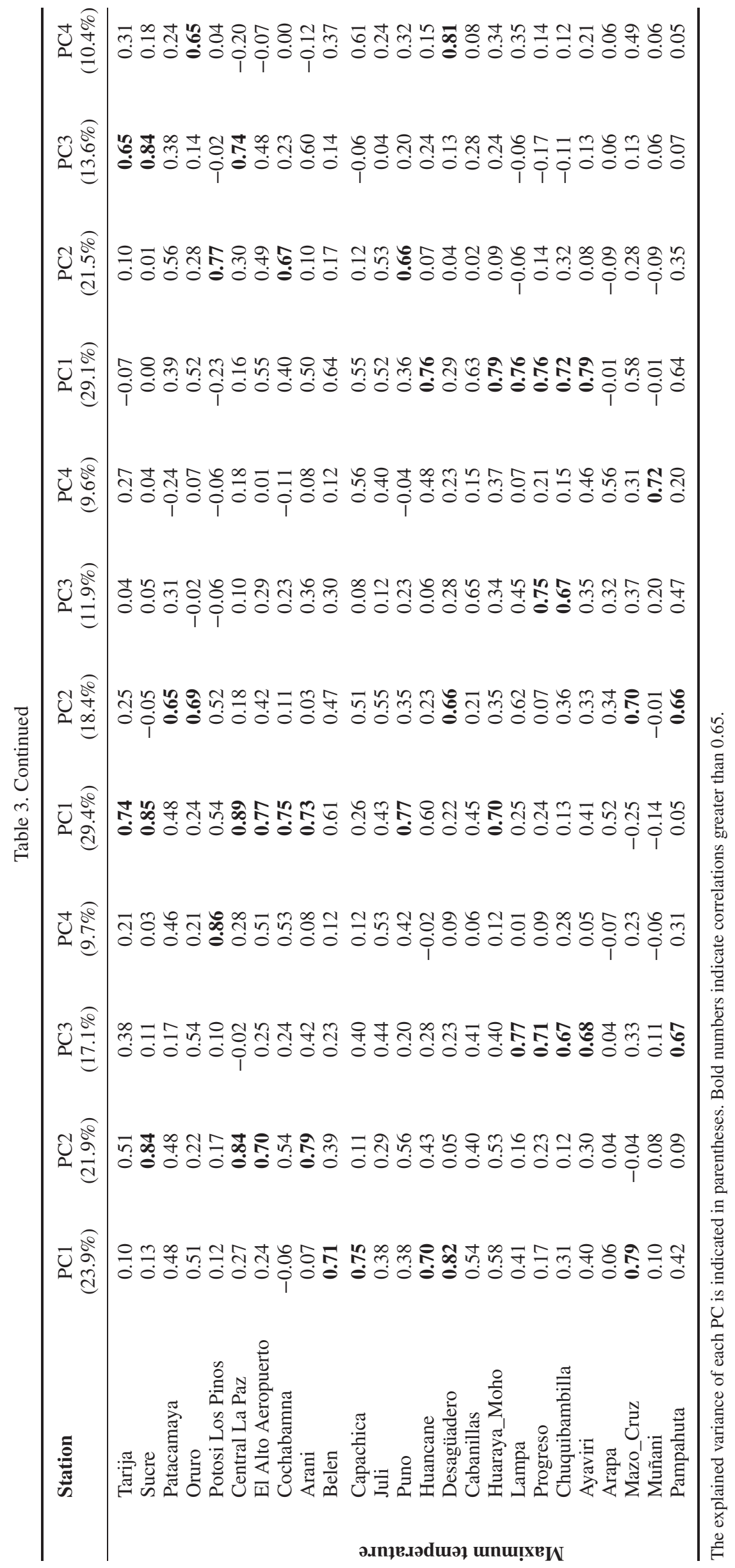


(a)
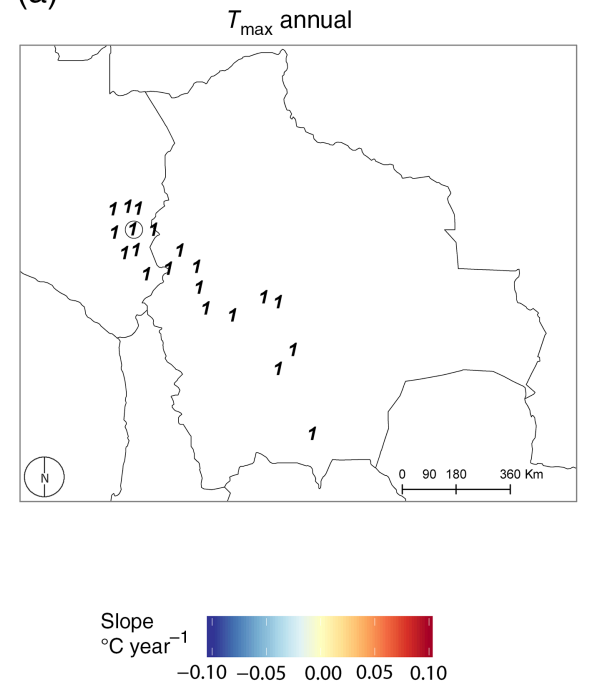

(b)

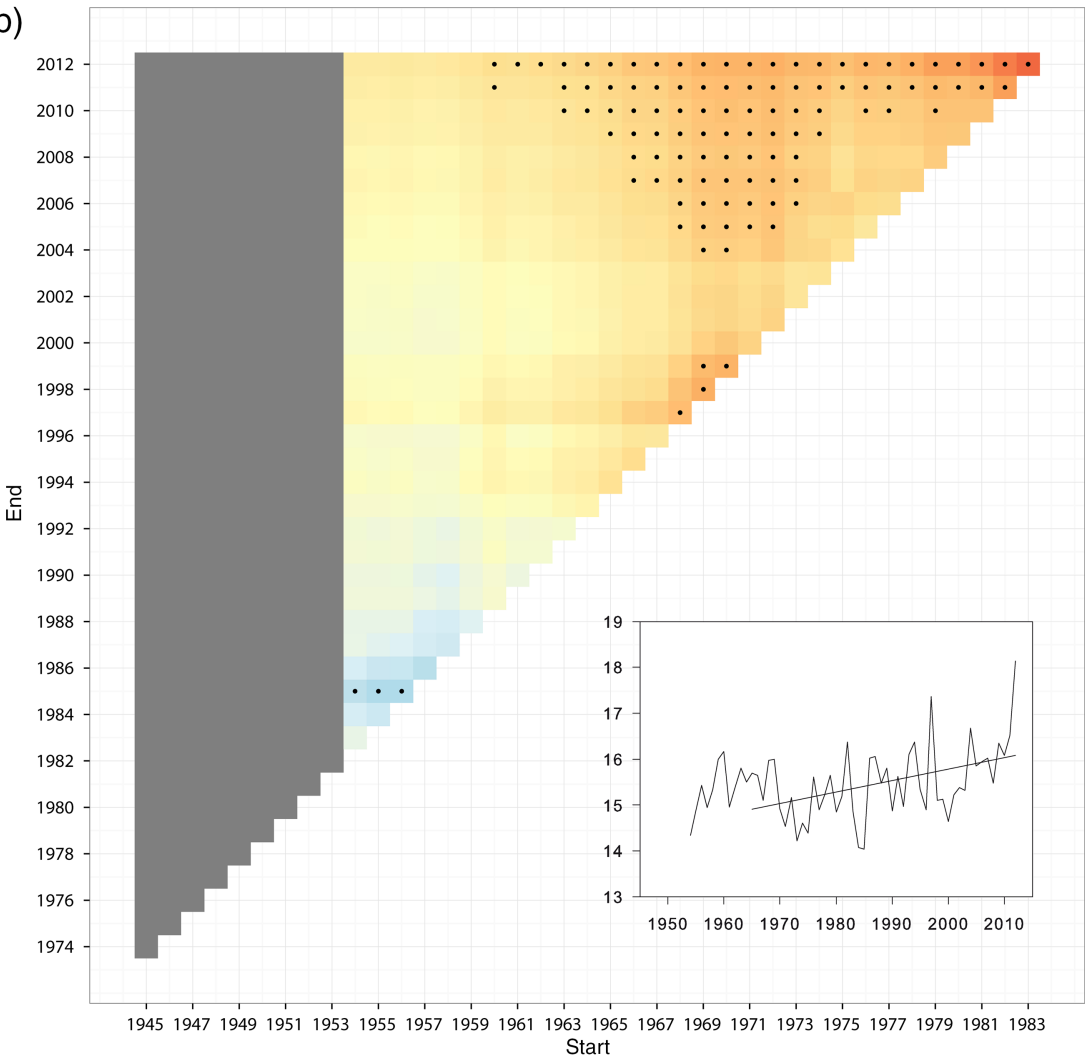

Figure 4. Meteorological stations that were highly correlated with the PC for annual $T_{\max }(r>0.65$, lower correlations are considered as unclassified) (a). Here and in subsequent figures: heat maps of the most correlated station (circled in (a) show the warming trends for all combinations of starting and ending dates, with a minimum duration of 30 years (b). Statistical significance $(p<0.05)$ is indicated by a black dot. The inset shows a time series of this station with a trend line for 1965-2012. Temporal series of PC1 corresponds to Ayaviri station.

stations had no significant correlations with any single $\mathrm{PC}$, and are thus best represented as different combinations of multiple PCs. Analysis of annual $T_{\min }$ values (Figure 7) indicates that only PC3 had a consistent temperature increase for the whole study period; the other components had trends for warming temperatures, but these were not statistically significant for most analysed periods. During the warm season (Figure 8), the PCs had a significant increase of $T_{\min }$ for the most recent years of the study period. PC1 represents several stations in Peru and Bolivia that had the most intense warming, and the results are consistent for all examined periods. For the cold season (Figure 9), the patterns had large differences in the sign of the trends (positive for PC2 and PC3, and negative for PC1 and PC4 for the 1965-2012 period) and for different periods.

4.3. Effect of ENSO and PDO on interannual variability of air temperature

Table 4 informs about the correlations of warm season (DJF) and cold season (JJA) temperatures with SO and PDO for each individual station for 1965-2012, 1955-2012 and 1945-2012 (when data were available). All but one station (Tarija, in Bolivia) had significant negative correlations of $\mathrm{SO}$ and $T_{\max }$ during the warm season and, except for this station, the correlations ranged from -0.39 to -0.65 . The largest correlations were in the eastern part of the study area, including all Peruvian stations and the Bolivian stations that were close to Titicaca Lake. Most stations where analysis was possible for longer periods had lower correlations for the longer time series. Almost the opposite pattern occurred for $T_{\max }$ during the cold season, with positive correlations at 21 of 25 stations and correlation coefficients mostly ranging from 0.29 to 0.52 . Similar to the warm season, the strength of the correlations was smaller for longer study periods. $T_{\min }$ had negative correlations with the $\mathrm{SO}$ at most sites during the warm and cold seasons, but the correlations were statistically significant in only seven stations during the warm season, and in three stations during the cold season.

The correlations between $T_{\max }$ and PDO basically had the opposite pattern, with all positive correlations during the cold season and mostly negative correlations during the warm season. These correlations were mostly smaller than those for $T_{\max }$ and SO. The correlations between $T_{\min }$ and PDO were mostly positive during both seasons and mostly smaller than those for $T_{\min }$ and SO. Only four and two of the correlations between $T_{\min }$ and PDO were statistically significant for the warm and the cold season, respectively.

Figure 10 shows the heat maps of the correlations of $T_{\max }$ with $\mathrm{SO}(\mathrm{a}-\mathrm{d})$ and $\mathrm{PDO}(\mathrm{e}-\mathrm{h})$ in stations representing each PC from Section 4.1. For the warm season, $T_{\max }$ was negatively correlated with $\mathrm{SO}$ for all starting and ending dates, although there was a slight decrease in the 


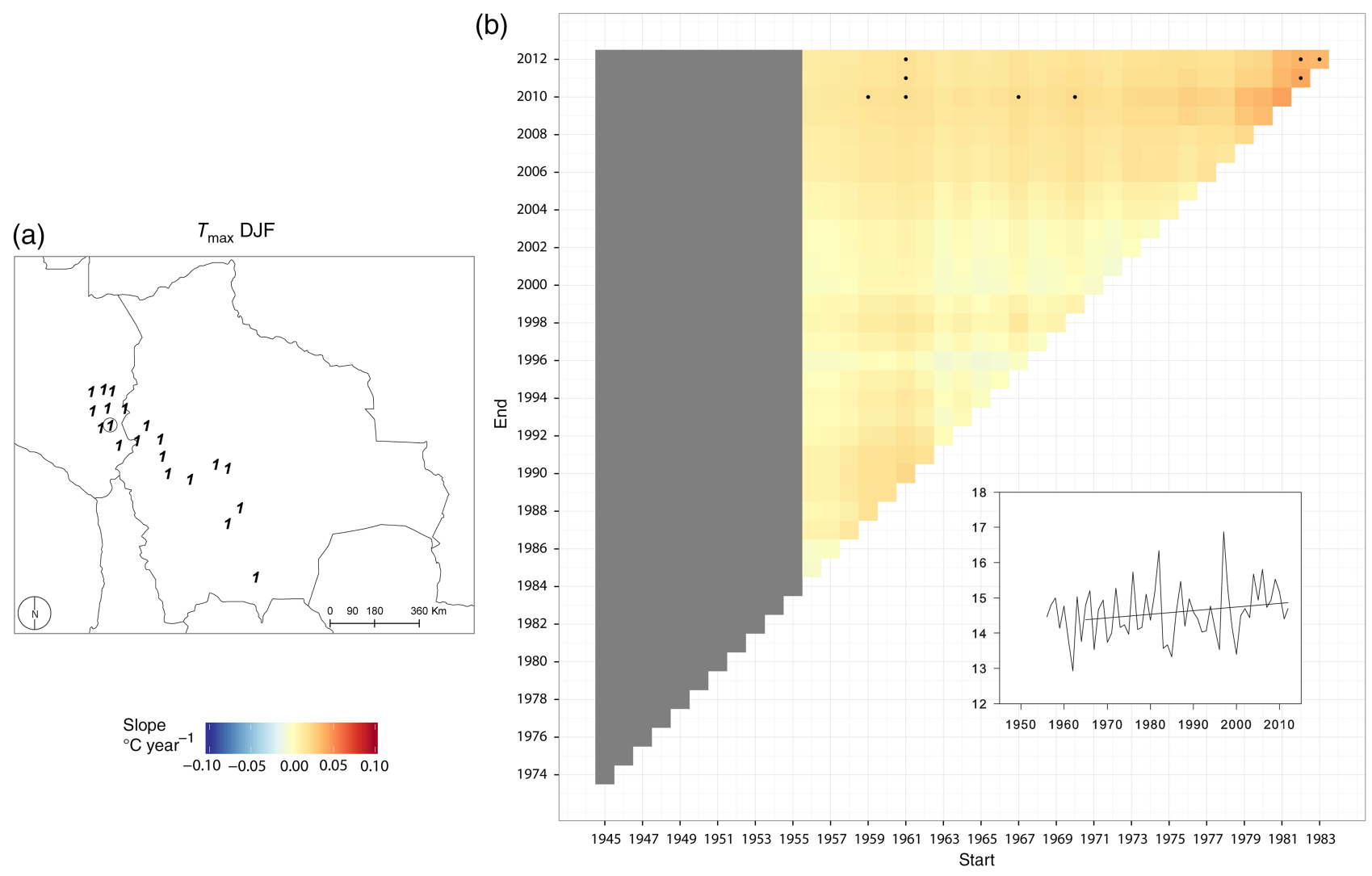

Figure 5. Meteorological stations that were highly correlated with the PC for the warm season $T_{\max }(r>0.65$, lower correlations are considered as unclassified) (a). Here and in subsequent figures: heat maps of the most correlated station (circled in (a) show the warming trends for all combinations of starting and ending dates, with a minimum duration of 30 years (b). Statistical significance $(p<0.05)$ is indicated by a black dot. The inset shows a time series of this station with a trend line for 1965-2012. Temporal series of PC1 corresponds to Huancane station.

magnitude of the correlations (Pearson's $r$ ) for series that ended in the last decade. For the cold season, there were positive correlations between the SO and stations representative of PC1 and PC2, most of which were statistically significant in the most recent time period; the correlation of SO and PC3 had major temporal variability, with a decadal fluctuation. During the warm season, the positive correlation of $T_{\max }$ with PDO was only statistically significant for series that started before 1965, suggesting a declining influence of the PDO over time. For the cold season, the three PCs tended to be negatively correlated with the PDO, although few of these correlations were statistically significant.

Figure 11 shows heat maps of the correlations of $T_{\min }$ with SO (a,b) and PDO (c,d) in stations representing each PC. For the warm season, $T_{\min }$ in the station representative of PC1 had a significantly negative correlation with SO, and a positive correlation with the PDO, with a decrease in the strength and significance of these relationships for series that ended in last years of the study period. The warm season PC2 had strong positive and statistically significant correlations with the SO for all time periods, but no significant correlations with the PDO. The stations representative of warm season $\mathrm{PC} 3$ and $\mathrm{PC} 4$ had no significant correlations with the $\mathrm{SO}$, but positive correlations with the PDO, except for analyses that included the last decade. For the cold season, PDO and SO had only a few statistically significant correlations stations corresponding to $\mathrm{PC} 1$ and PC2 for any combination of starting and ending years. However, stations representative of cold season PC3 had significant negative correlations with the SO and significant positive correlations with the PDO, except when the time series included the most recent decade.

\section{Discussion and conclusions}

To our knowledge, this is the first study of recent temperature changes in both, the Peruvian and Bolivian Altiplano and the Bolivian Andean slopes, and the relationship of these temperature changes with ENSO and the PDO. We used a high-quality database, with monthly data from 25 meteorological stations from October 1965 to September 2013 (hydrological years 1965-2012). Some of the longer records enabled assessment of the influence of the different time periods on the warming rate.

Annual $T_{\max }$ had a clear increase in the entire study region, with warming trends generally between 0.15 and $0.25^{\circ} \mathrm{C}$ decade $^{-1}$ for the period of $1965-2012$. This exceeds the reported values of $0.11^{\circ} \mathrm{C}$ decade $^{-1}$ for Bolivia (Seiler et al., 2013a) and $0.12^{\circ} \mathrm{C}$ decade $^{-1}$ for the Peruvian Andes (Lavado-Casimiro et al., 2013), which were determined for similar time periods. The warming trends in the present research are closer to the $0.2^{\circ} \mathrm{C}$ decade $^{-1}$ warming trend reported for the basin of 
(a)

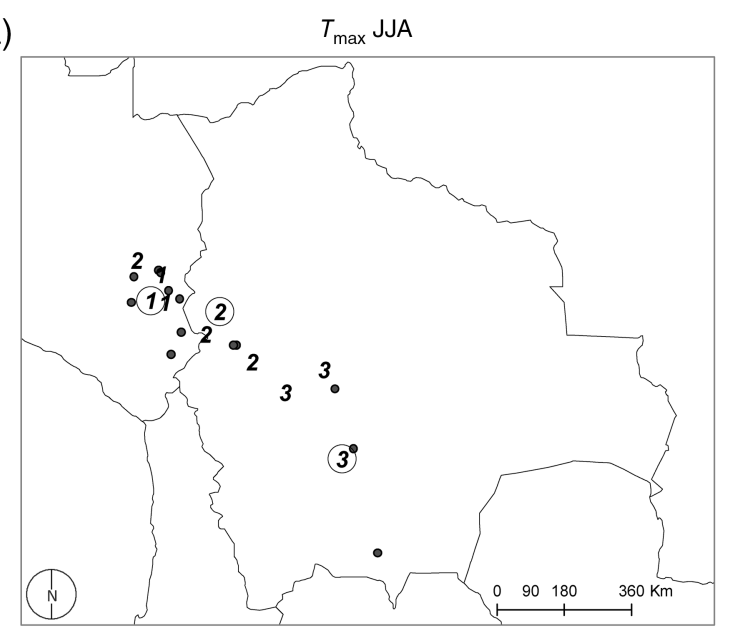

(c)

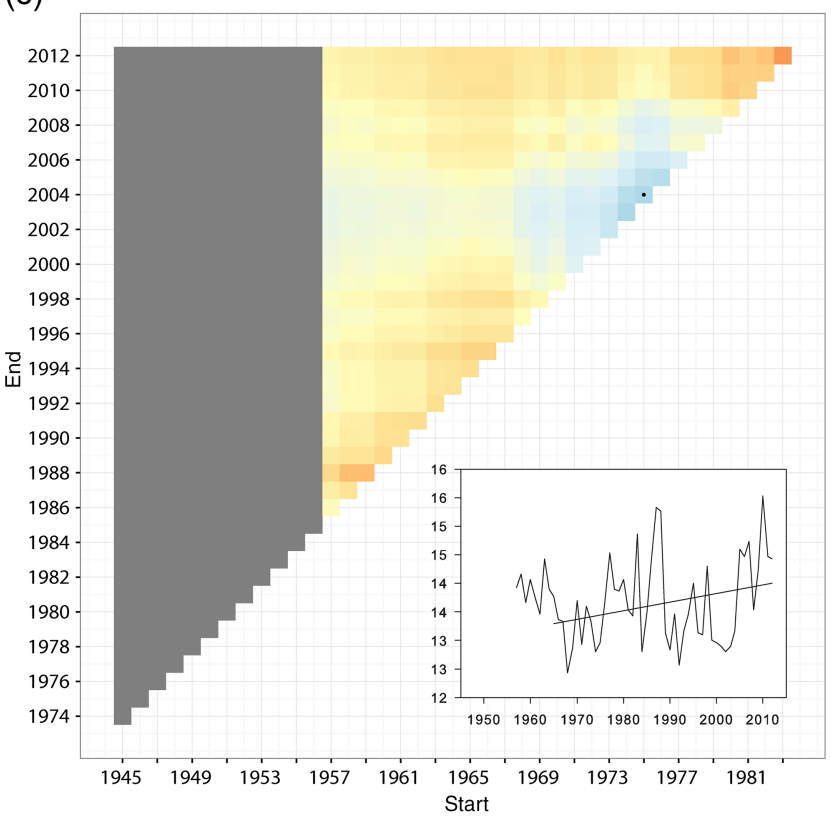

(b)

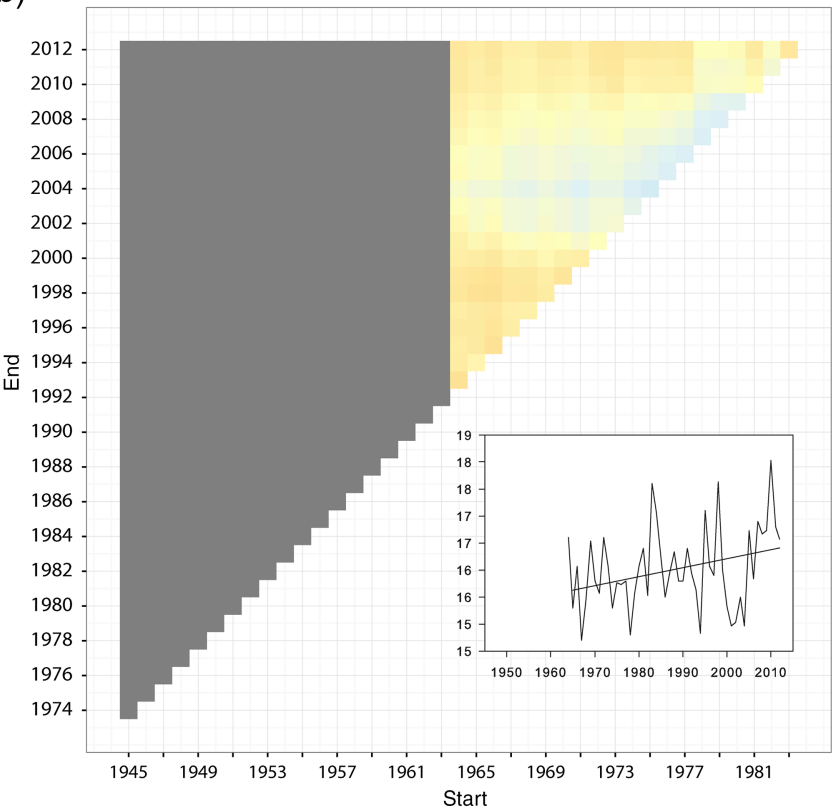

(d)

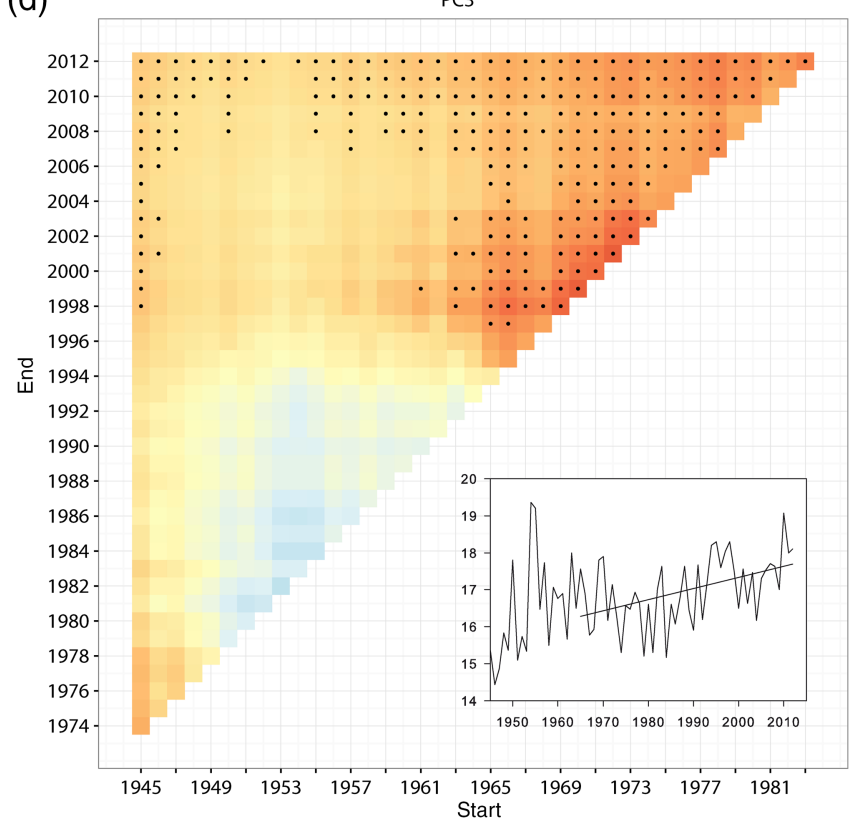

Figure 6. Meteorological stations that were highly correlated with three PCs for the cold season $T_{\max }(r>0.65$, lower correlations are considered as unclassified) (a). Here and in subsequent figures: heat maps of the most correlated station (circled in (a) show the warming trends for all combinations of starting and ending dates. Statistical significance $(p<0.05)$ is indicated by a black dot. The inset shows a time series of this station with a trend line for 1965-2012. Temporal series of PC1, PC2 and PC3 correspond to Cabanillas, Patacamaya and Potosi stations, respectively (b-d).

the Mantaró river in Peru in the period of 1965-2002 (López-Moreno et al., 2014), or the $0.32{ }^{\circ} \mathrm{C}$ decade $^{-1}$ for the tropical Andes for the period 1974-1998 (Vuille et al., 2000). Our results also indicated that $T_{\min }$ also increased in the study area, but this increase was much smaller, from 0.05 to $0.27^{\circ} \mathrm{C}$ decade $^{-1}$, and few locations had statistically significant increases in $T_{\min }$.

Lavado-Casimiro et al. (2013) reported that $T_{\max }$ increased at a greater rate in the Peruvian Amazon-Andes basin during the warm season (DJF) than the cold season (JJA). In contrast, Seiler et al. (2013a) studied Bolivia and reported stronger warming during the austral winter. The present study, with data from 25 stations, informs about the existence of a gradient from the northwest to southeast in the magnitude of the DJF and JJA trends of $T_{\max }$. This gradient explains the apparent discrepancy between both studies. Most of our analysed series of $T_{\max }$ had break points in their temporal evolution by late 1990s or early 2000s. There were fewer break points for the $T_{\min }$ series, and they were more common from the 1970s to recent years.

PCA allowed us to assess how $T_{\max }$ and $T_{\min }$ at the annual and seasonal levels changed over time in the study area. Thus, the temporal evolution of annual $T_{\max }$ and 


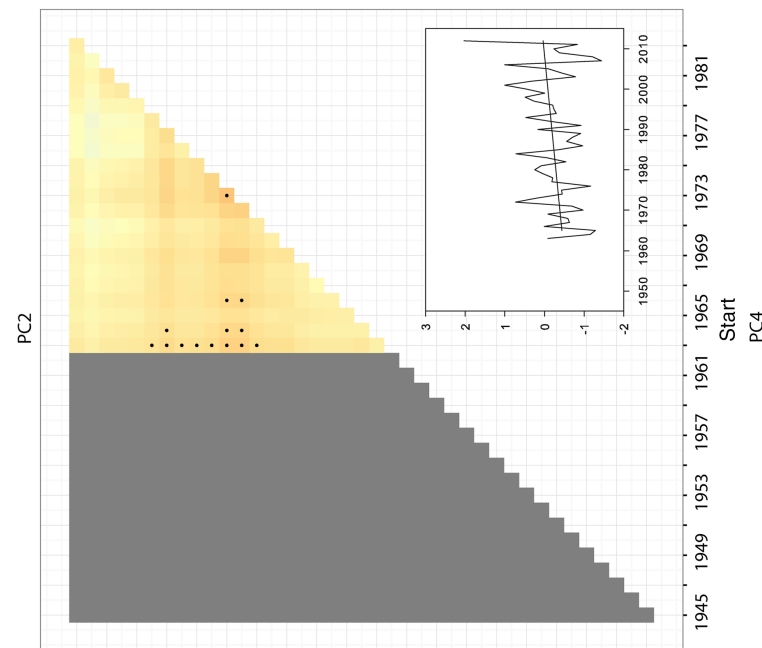

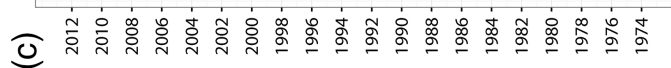

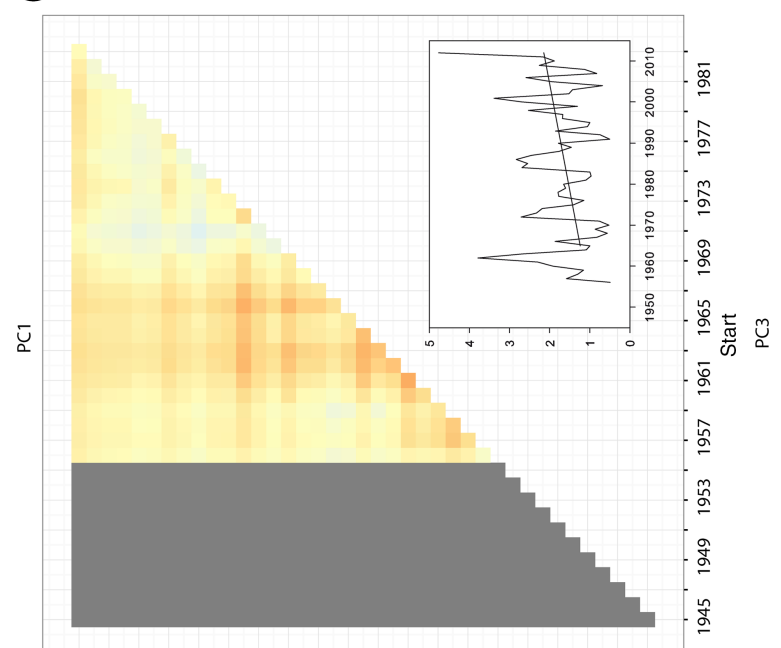

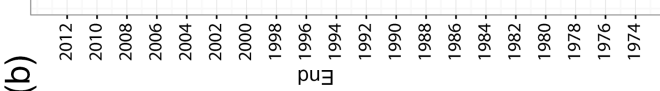

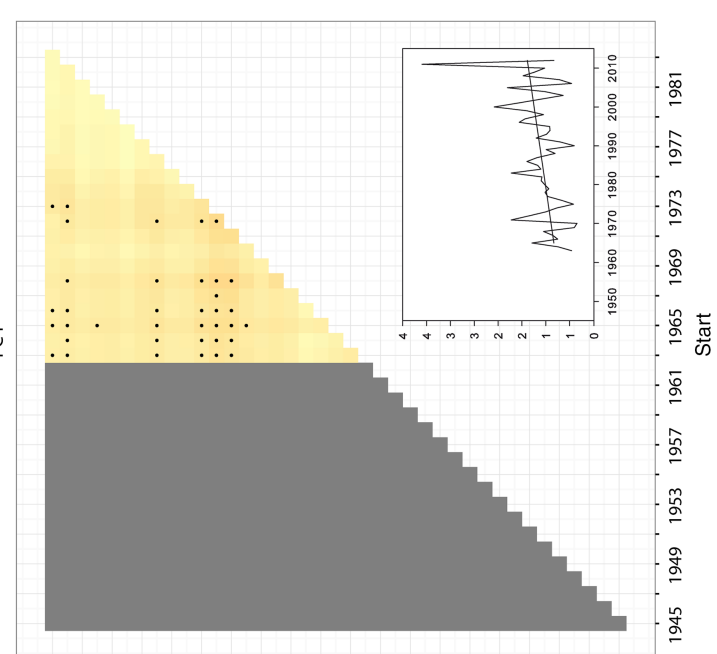

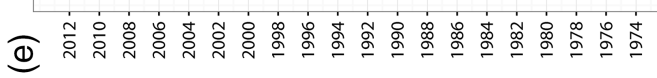

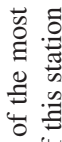

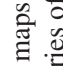

䒿品

$\ddot{\mathrm{s}} \cdot \overrightarrow{\mathrm{g}}$

50

过 $\frac{1}{2}$

苞

至总

$\Xi$ 寄.

एँ

牙 $\frac{\pi}{3} \cdot \frac{5}{0}$

बิ

จे

氜

疍. 


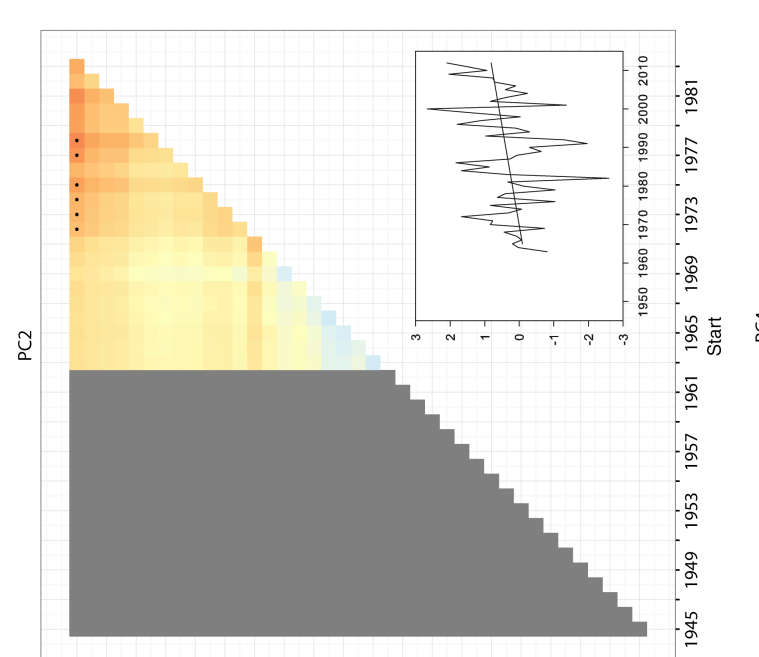

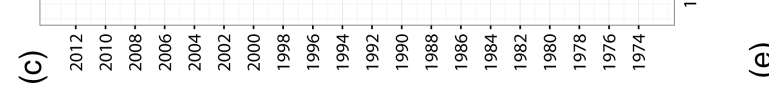

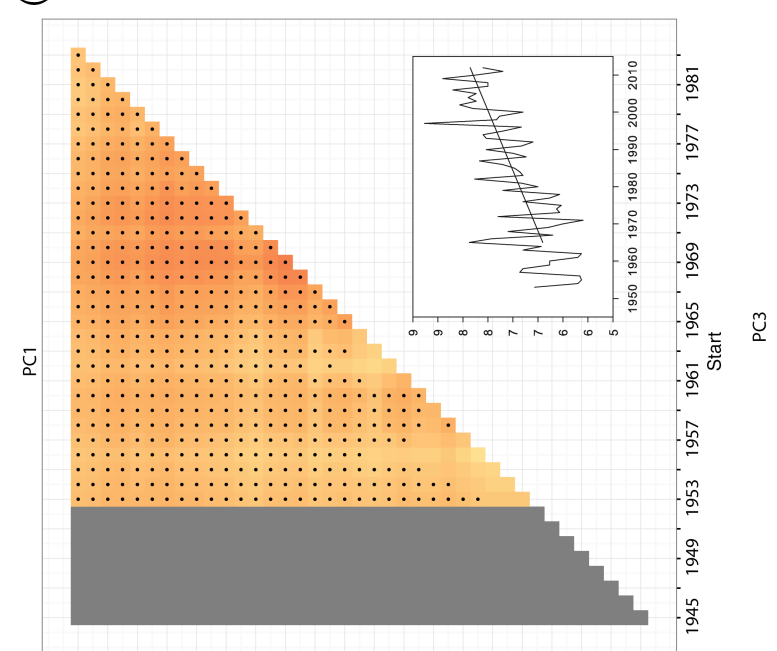

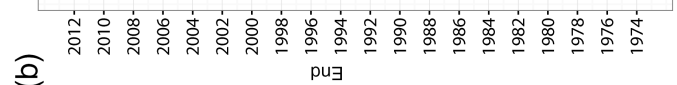

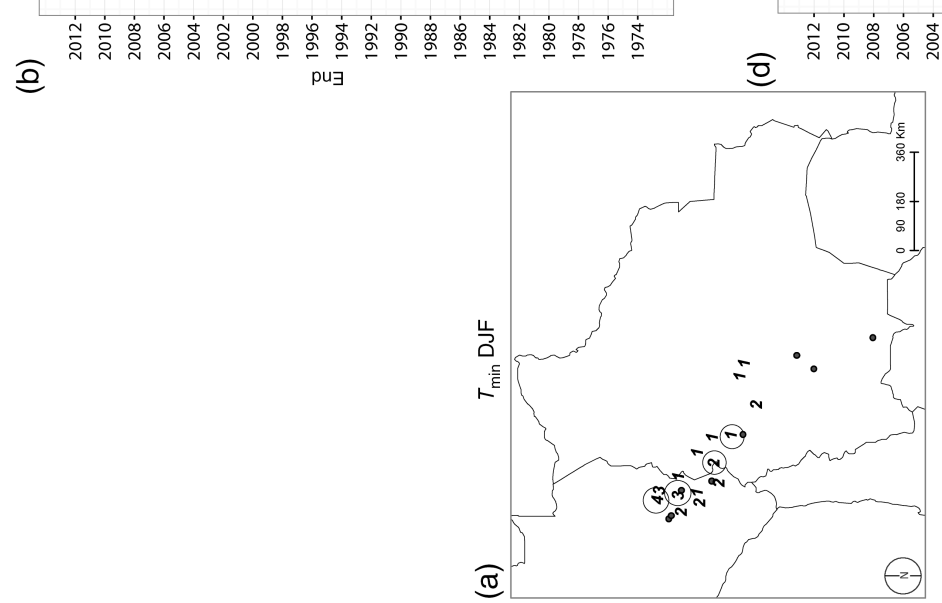

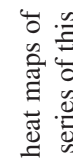

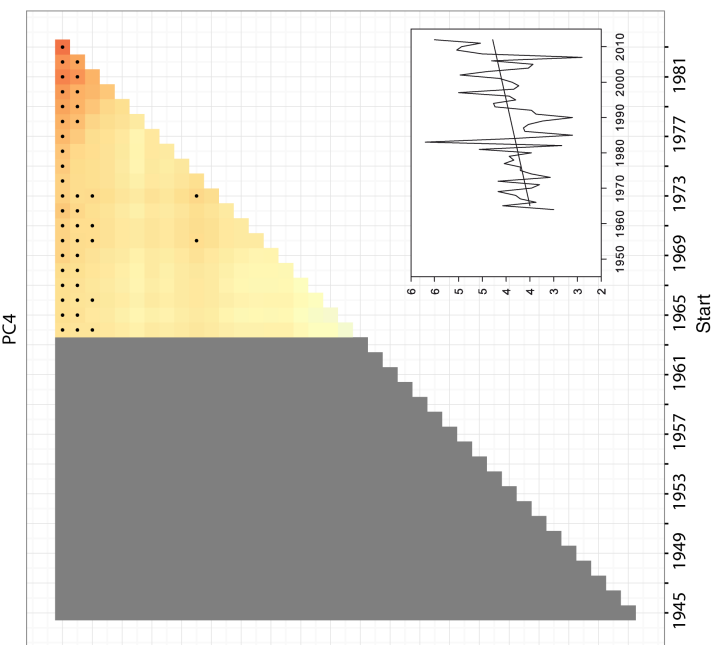

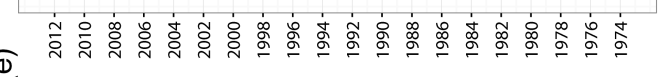
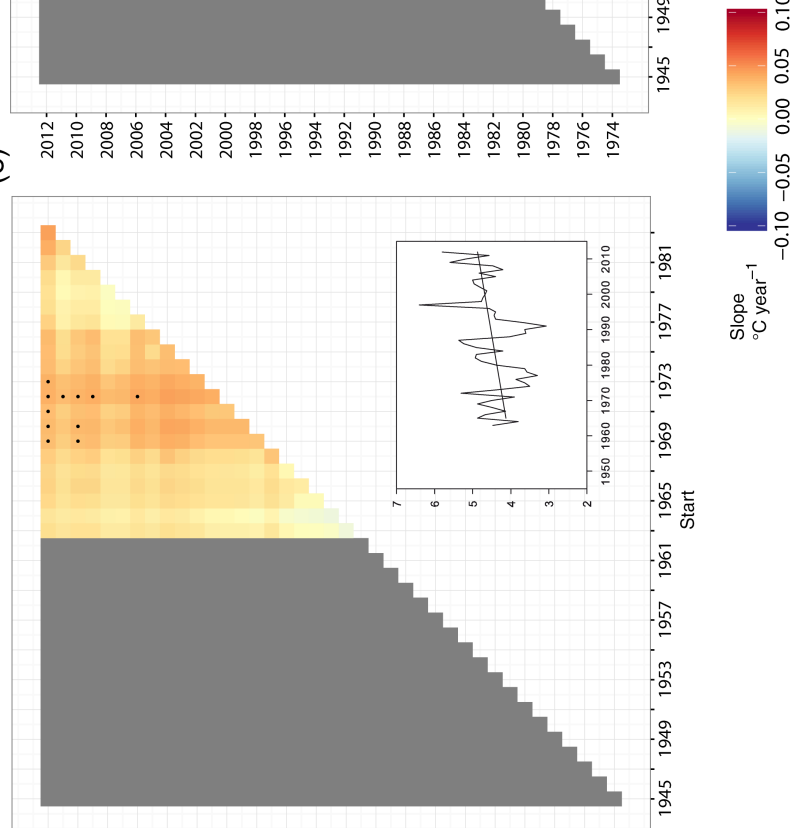

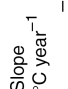




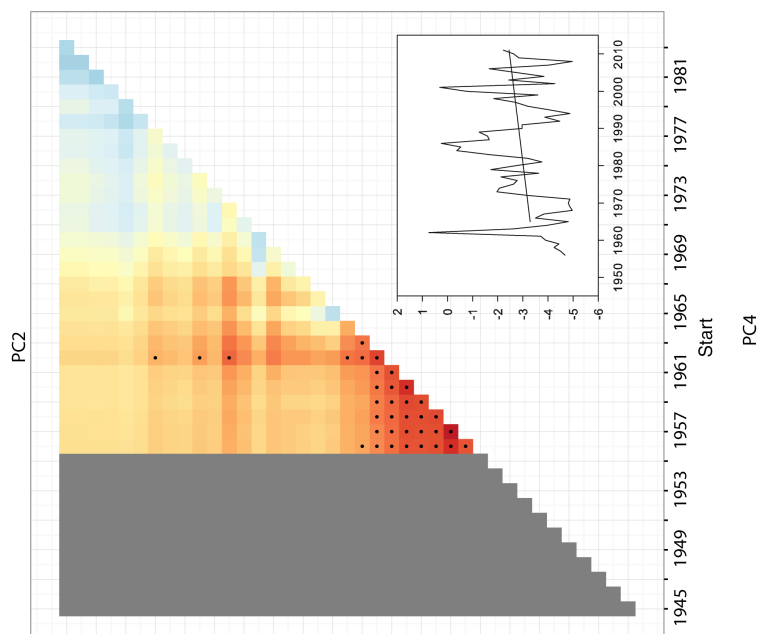

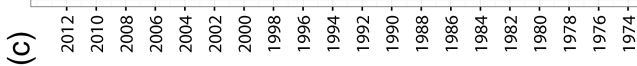

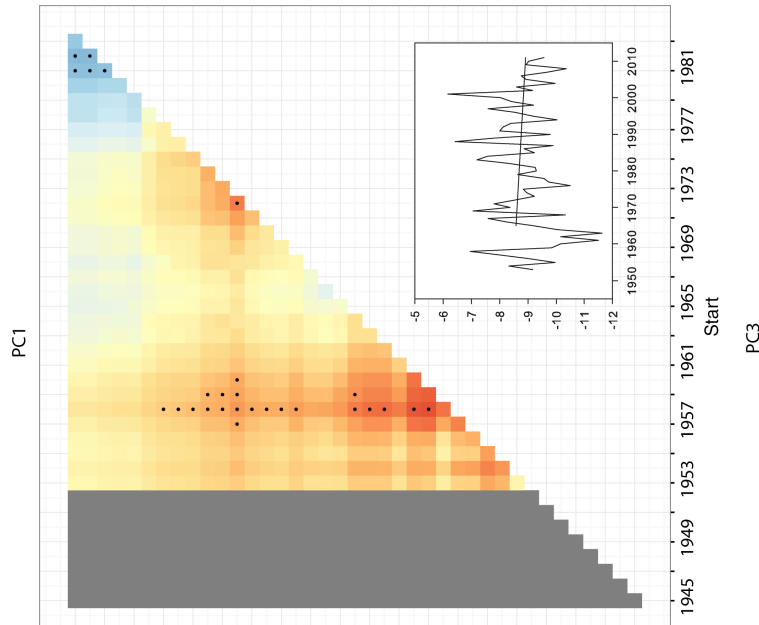

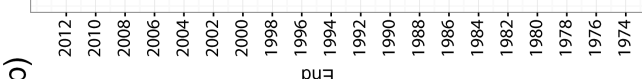

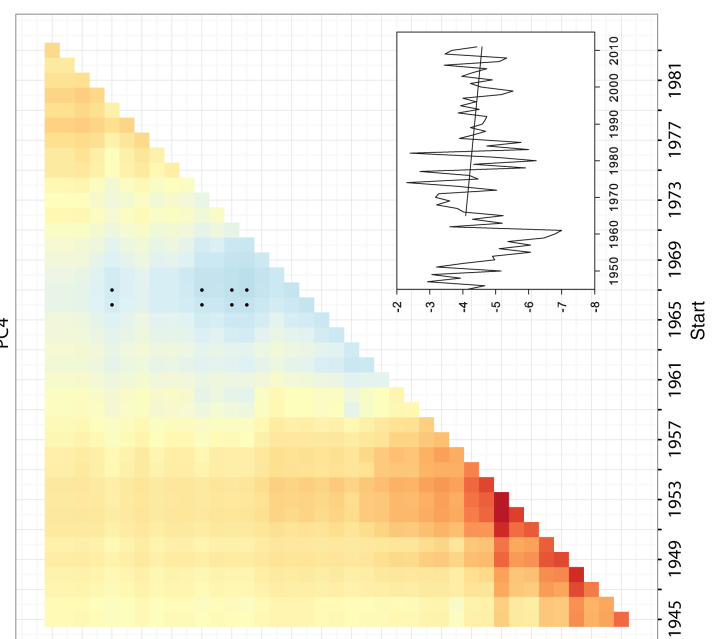

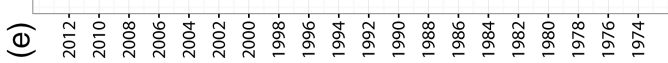

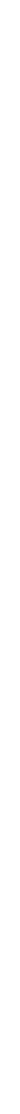
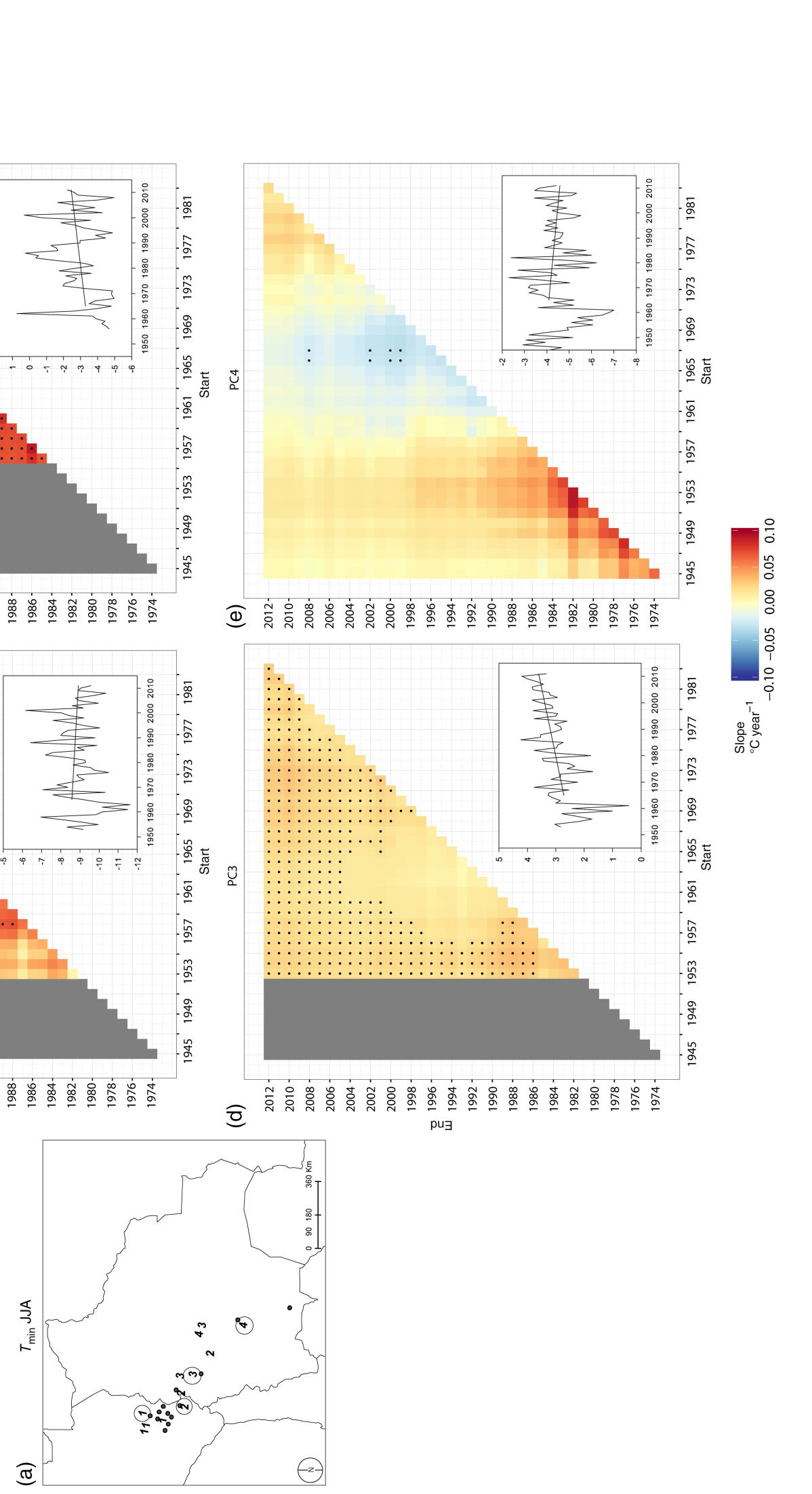

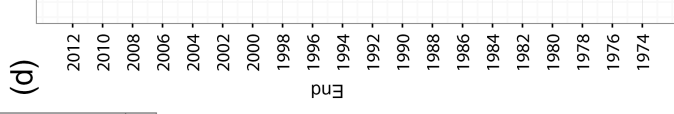
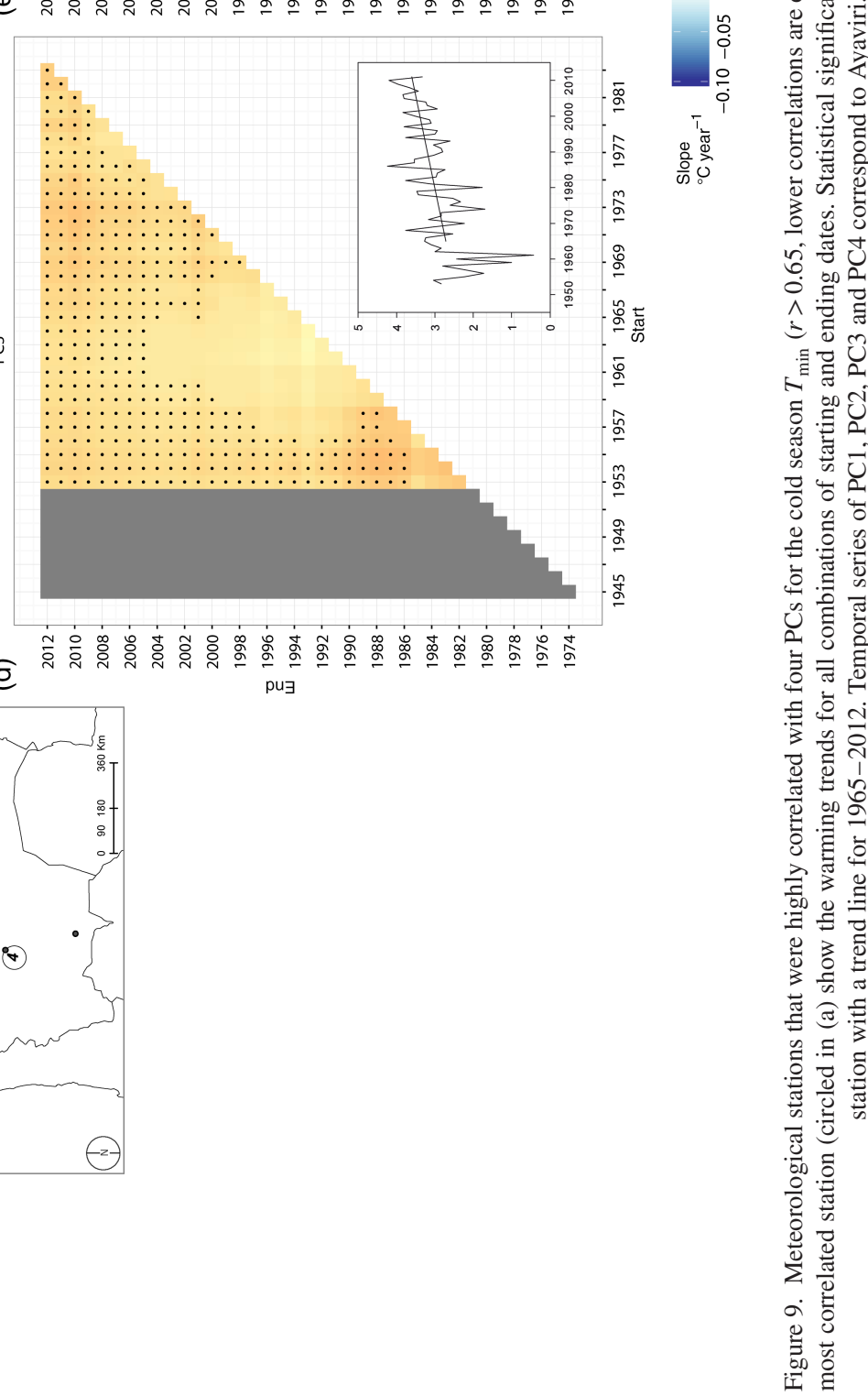
Table 4. Correlation of the Southern Oscillation index (SOI) and the Pacific Decadal Oscillation (PDO) with $T_{\max }$ (top) and $T_{\min }$ (bottom) for different time periods in the 25 stations.

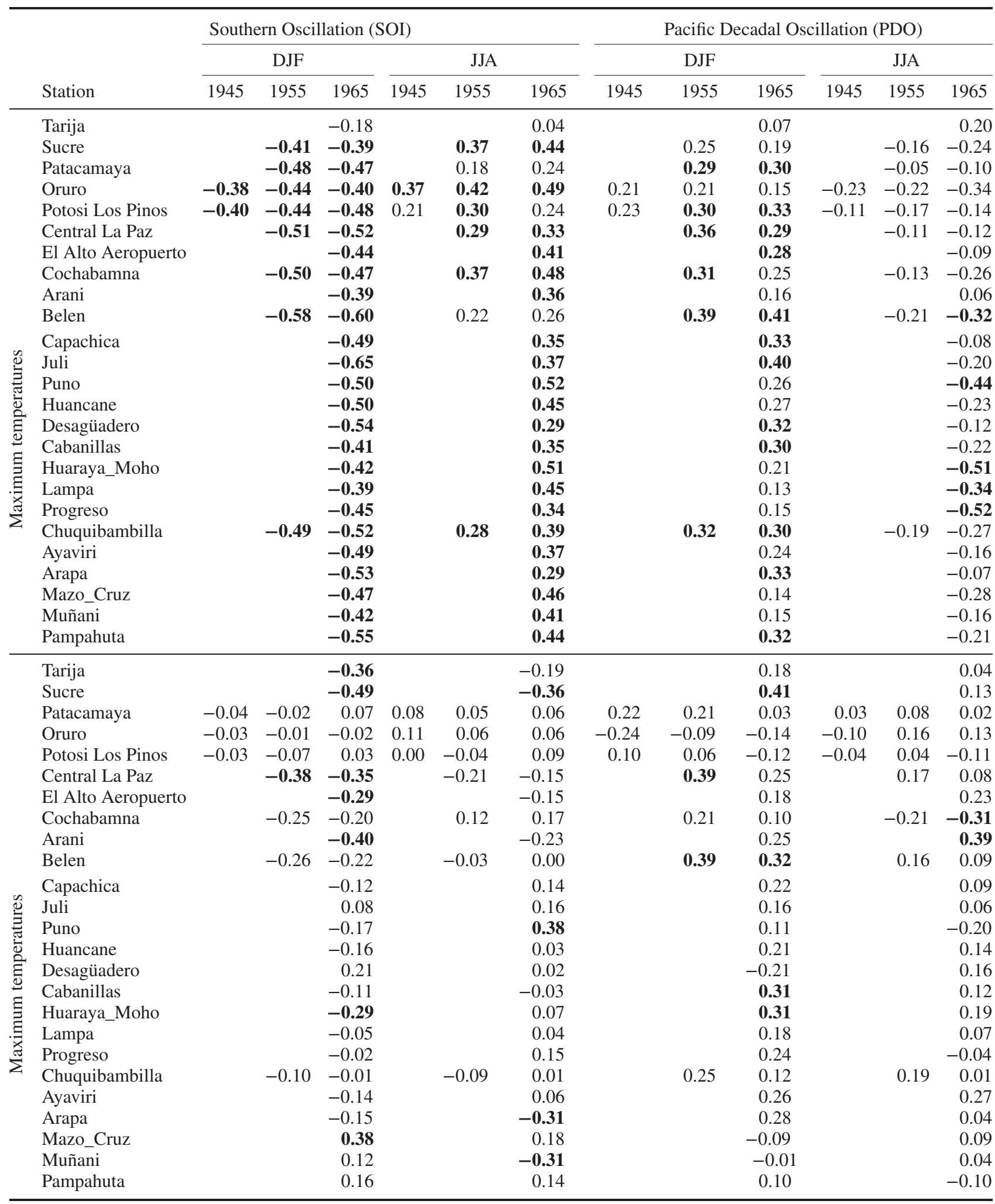

Bold numbers indicate significant trends $(\alpha<0.05)$.

warm season $T_{\max }$ was very similar over the whole study area, and these changes can be summarized by a single PC that is highly correlated $(r>0.65)$ with the 25 analysed stations. $T_{\max }$ during the cold season had a more complex spatial distribution, and three different PCs were needed to explain most of the interannual variability, with a shift in the shape of the temporal evolution and increased warming rates in the western stations.

$T_{\min }$ at the annual and seasonal levels required three or four PCs to explain $70 \%$ of the variance, and analysis 
of the spatial distribution of the PCs indicated no clear spatial pattern, with nearby stations having very different interannual trends. This indicates the influence of local factors and microclimate on the magnitude and temporal evolution of $T_{\min }$, as also reported for other regions and related to the probability of occurrence of thermal inversions (Stahl et al., 2006; Kattel and Yao, 2013).

Our results indicated that the evolution of temperature in the study area, similarly to wide areas of South America, was closely linked to ENSO and the PDO. As indicated by Garraeud et al. (2009) and Tedeschi et al. (2013) at a regional scale El Niño episodes (positive SO) are associated with: (1) below normal rainfall over tropical South America, (2) above normal precipitation over the southeastern portion of the continent and central Chile and (3) warmer than normal conditions over tropical and subtropical latitudes included the Atiplano region. Opposite rainfall and temperature anomalies are observed during $\mathrm{La}$ Niña episodes (negative SO). On the other hand, The PDO is often described as ENSO-like, because the spatial climate implications of its warm and cold phase that mirrors those of El Niño and La Niña events (Garreaud and Battisti, 1999). However, the causes of the PDO and its links with ENSO are not fully understood yet (Schneider and

(a)

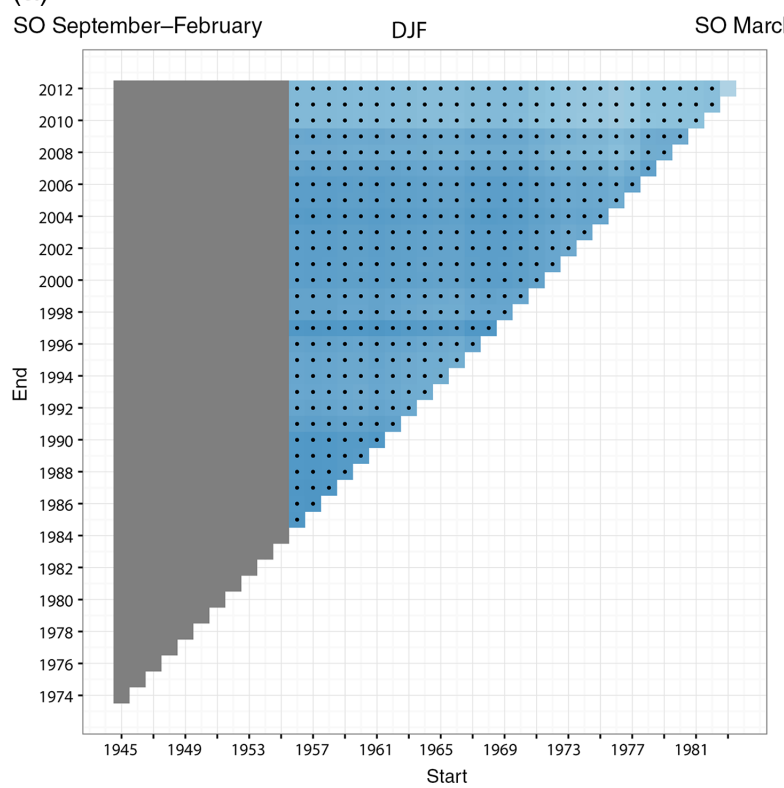

(b)

(c)

JJA PC2

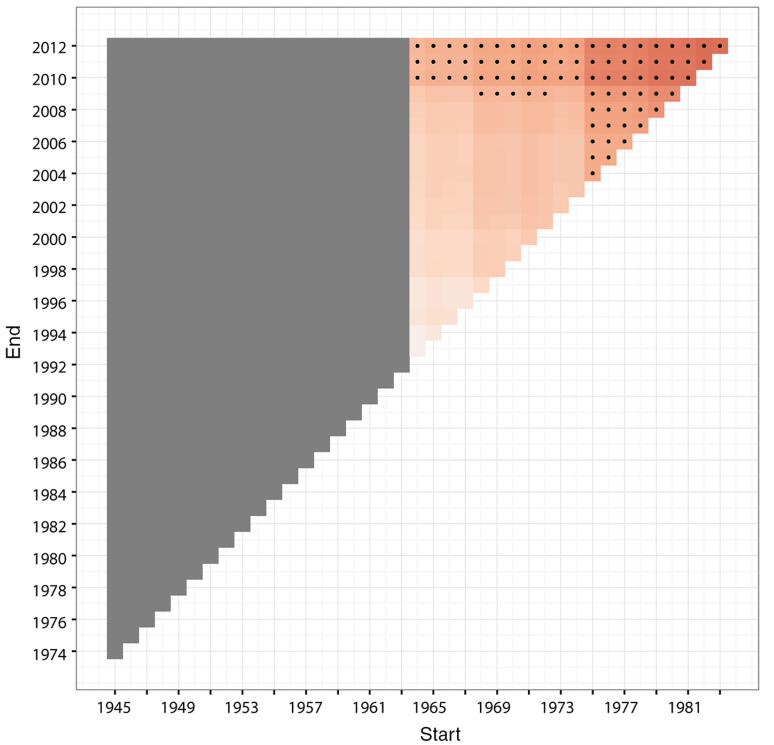

(d)

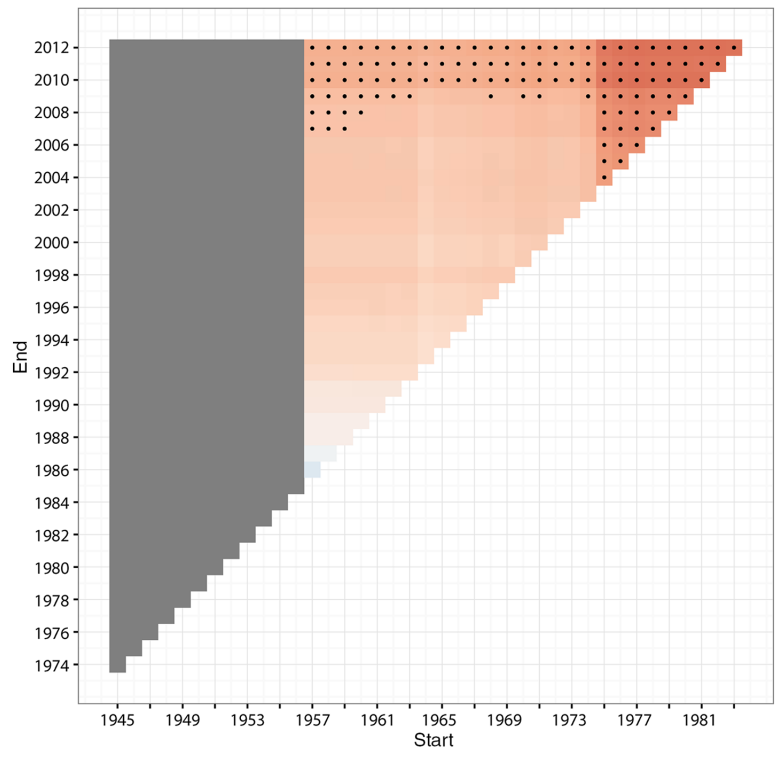

JJA PC3

Pearson's $r$

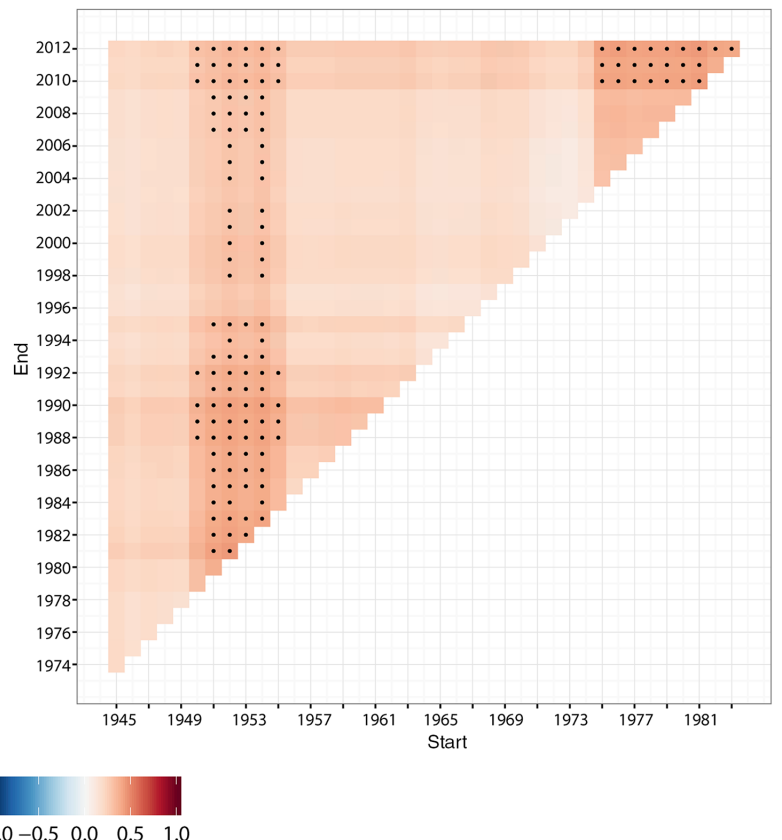

Figure 10. Heat maps of correlations of all possible combinations of starting and ending dates (minimum duration of 30 years) between SO (a-d) and PDO $(\mathrm{e}-\mathrm{h})$ with $T_{\max }$ in stations with the highest correlations for each identified PC. Statistical significance $(p<0.05)$ is indicated by a black dot. 
(e)

(f)

PDO September-February

PDO March-August
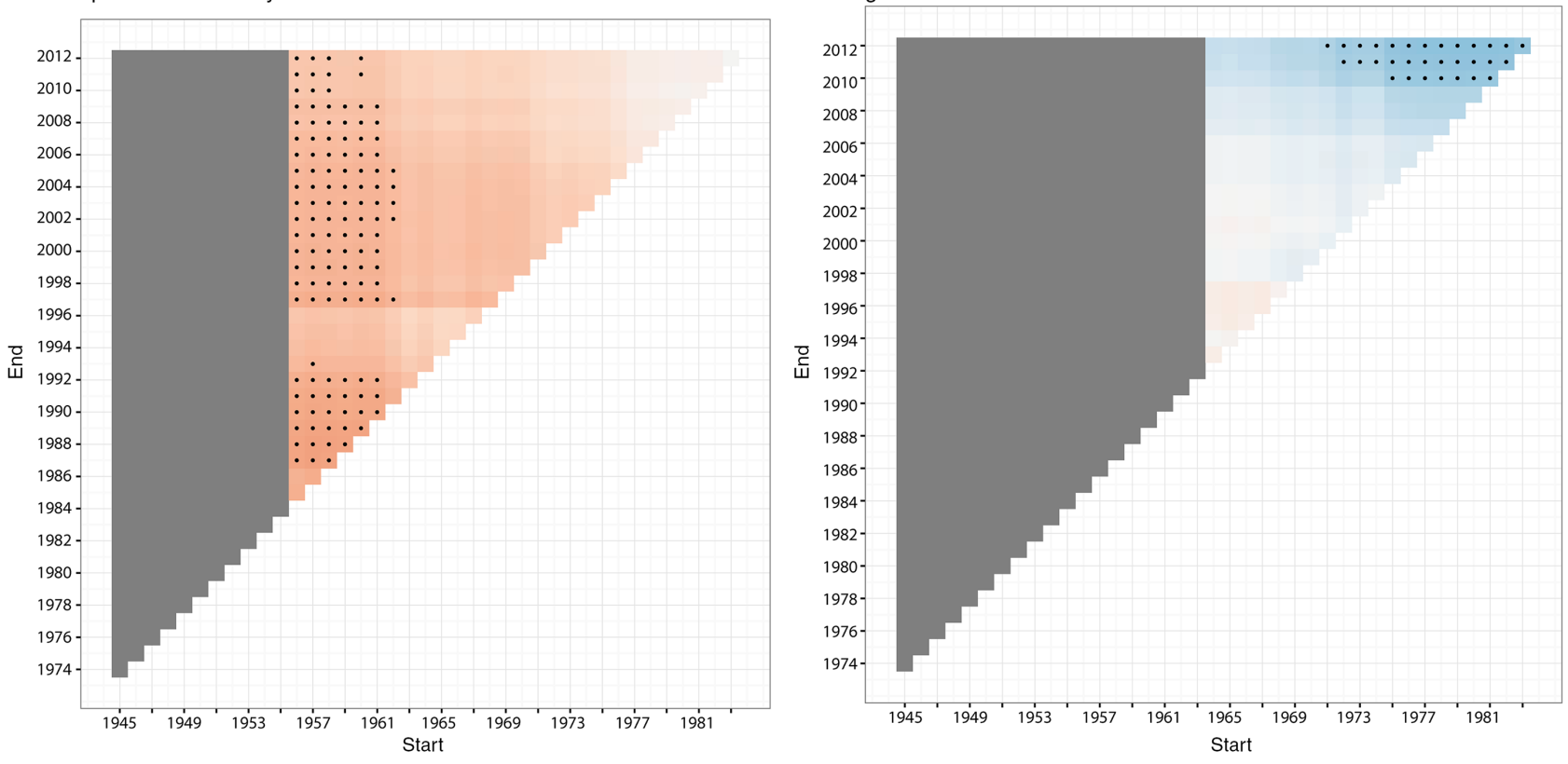

(g)

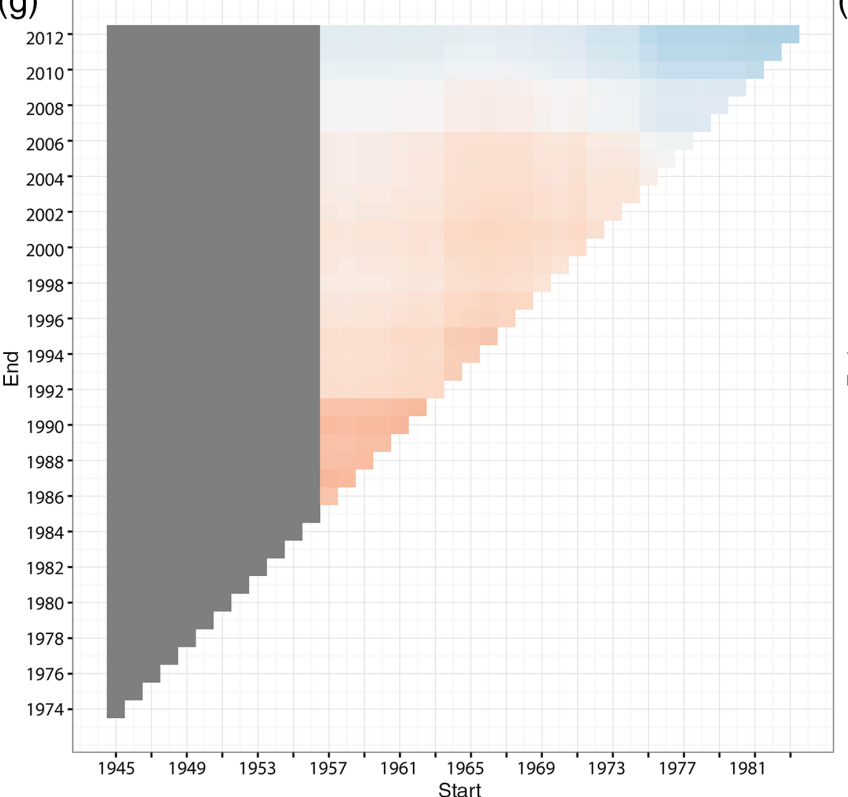

(h)

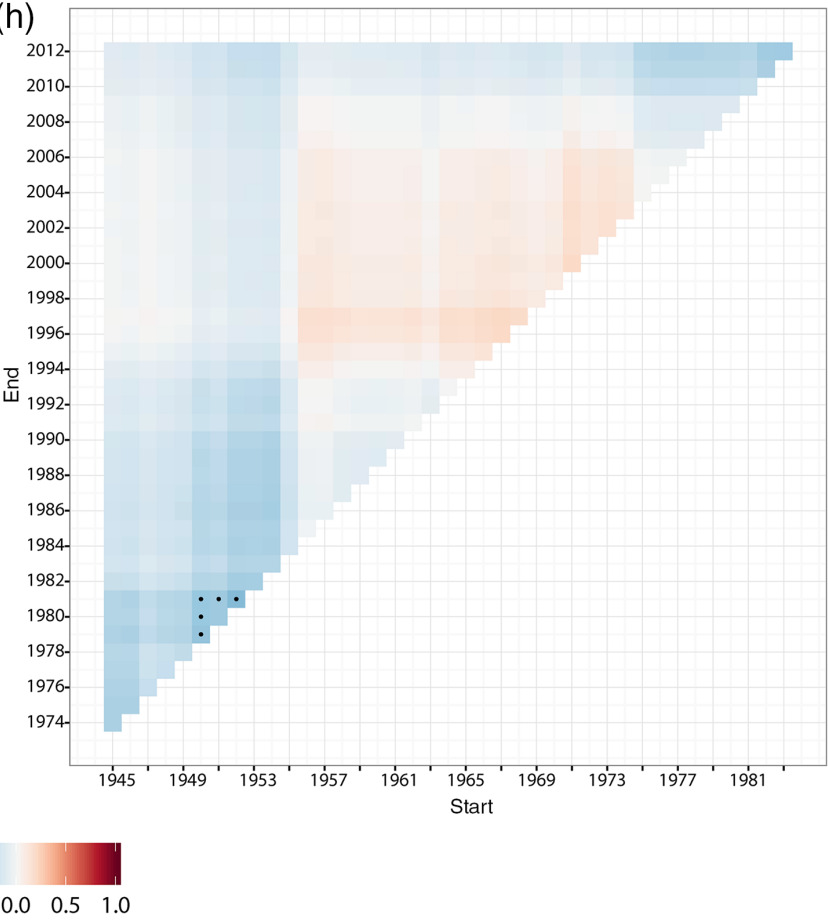

Figure 10. Continued.

Cornuelle, 2005). The aggregated 6-month values prior to the last month of each season (DJF and JJA) had maximum correlations with the temperature series. $T_{\max }$ in the warm and cold seasons was significantly correlated with the SO and PDO in the warm season (positive and negative correlations, respectively) and the cold season (negative and positive correlations, respectively). Such seasonal differences also were reported by Seiler et al. (2013a), but they were not as obvious as those presented in this study. Probably such difference is due to use the of $T_{\text {mean }}$ data instead of $T_{\max }$ and $T_{\text {min }}$ separately. Moreover, the correlations between temperature and the $\mathrm{SO}$ were greater than those between temperature and PDO. Both of these atmospheric circulation patterns in both seasons had similar spatial patterns in their correlations with temperature, with decreasing coefficients in the more eastern stations. $T_{\text {min }}$ had lower correlation coefficients, and very few stations had statistically significant relations of $T_{\min }$ with SO and PDO. Again, this provides an evidence on the importance of local factors and microclimate on the evolution of $T_{\min }$. For $T_{\min }$, most stations were negatively correlated with the SO and positively correlated with the PDO during the warm and the cold seasons. The correlation coefficients with SO and PDO reported in this study are higher 
(a)
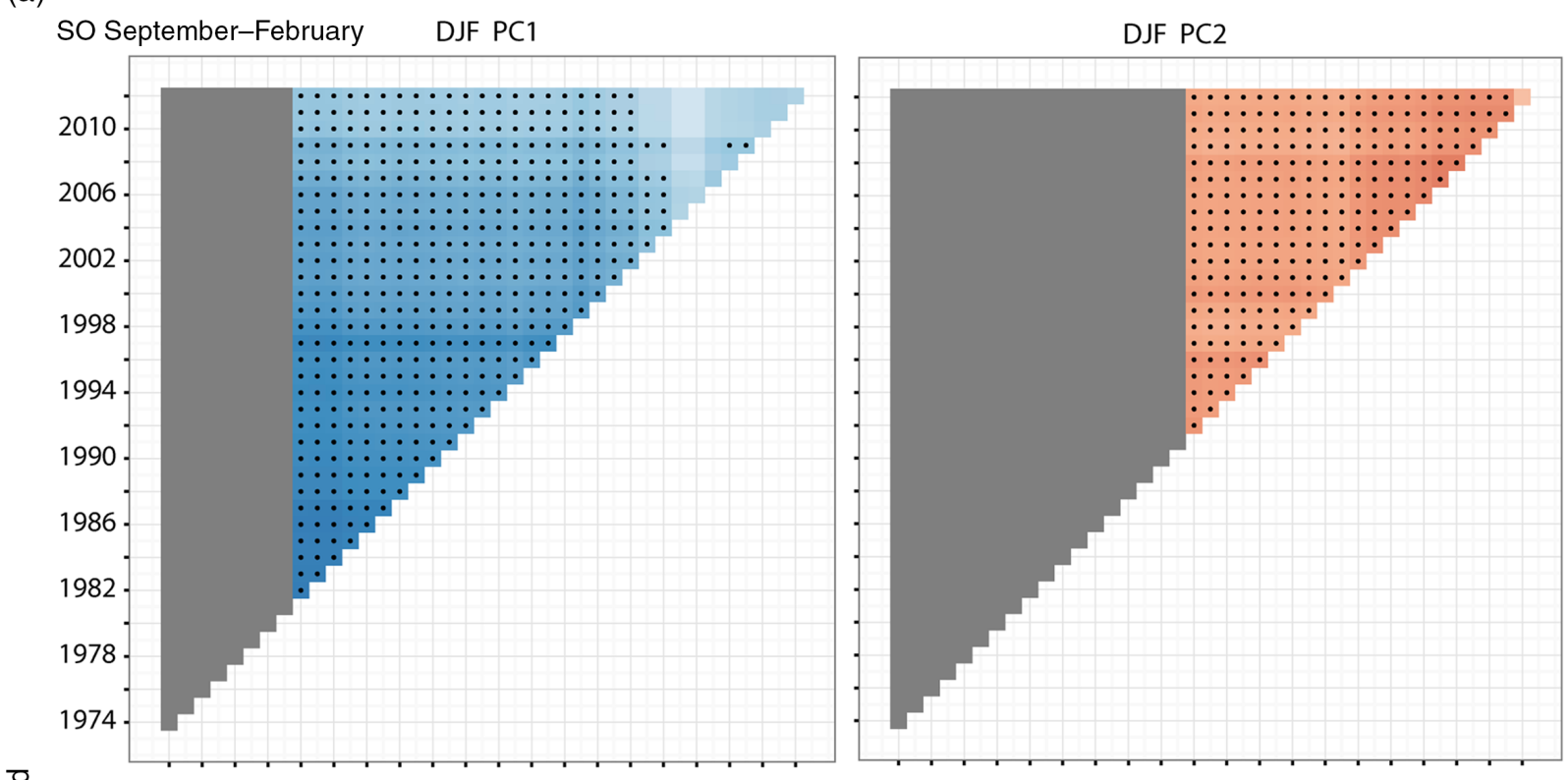

문
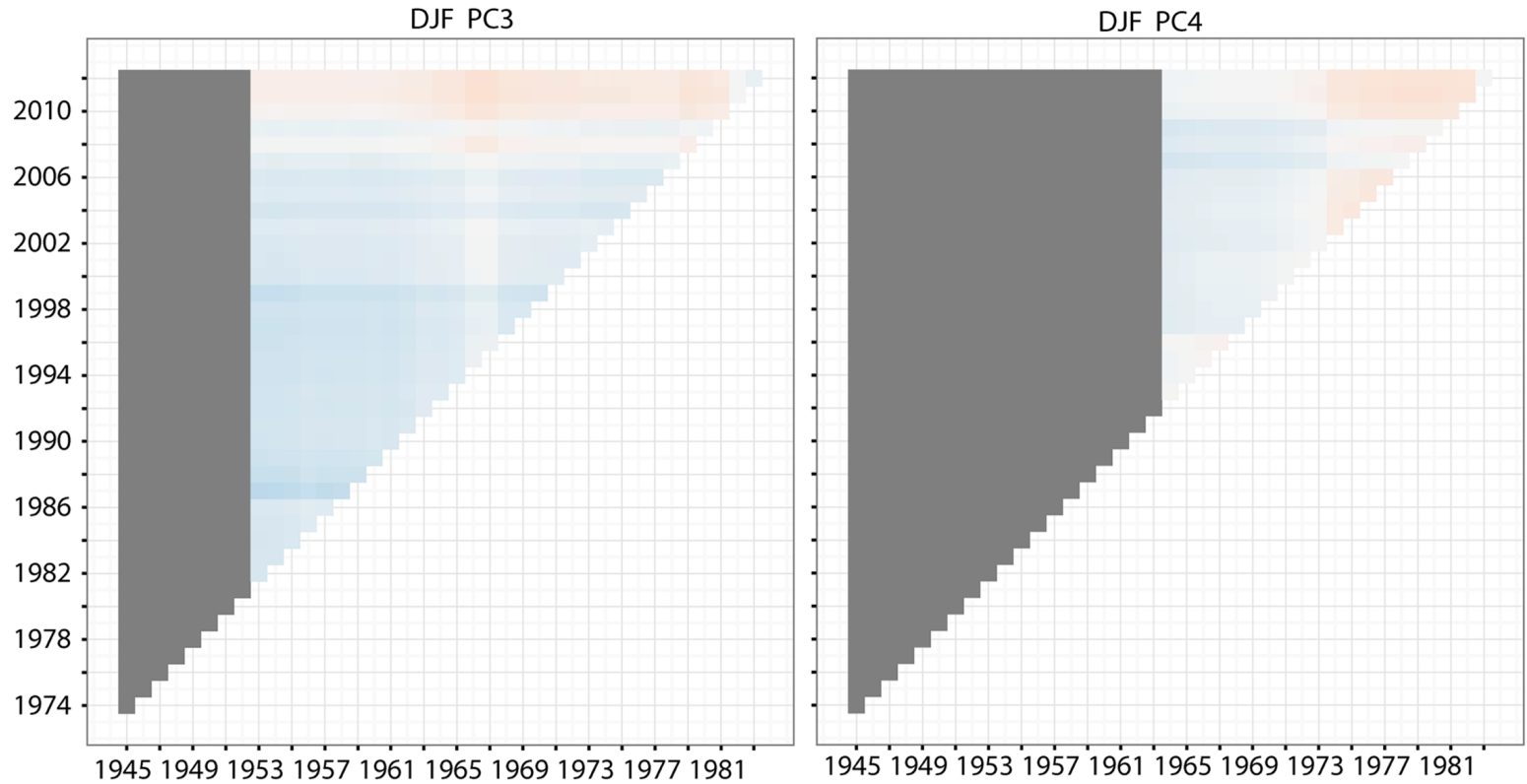

Start

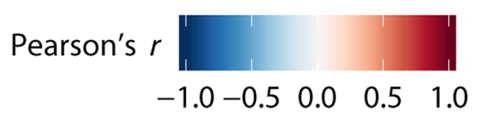

Figure 11. Heat-maps of correlations of all possible combinations of starting and ending dates (minimum duration of 30 years) between SO (a,b) and PDO (c,d) with $T_{\min }$ in stations with the highest correlations for each identified PC. Statistical significance $(p<0.05)$ is indicated by a black dot.

than those reported by Seiler et al. (2013a) for the Bolivian Andes slopes and the Altiplano, and also higher than those reported in other studies of Peru and the tropical Andes (Vuille et al., 2003; Lavado-Casimiro et al., 2013). These differences are probably due to the 6-month aggregation of SO and PDO performed in our analyses. Moreover, these previous studies used mean temperatures for analysis and we used $T_{\max }$ values.

One of the most interesting findings of the present study is that the rate of temperature increase varied for different study periods (Burn and Elnur, 2002). In particular, when the time series started earlier (1945, 1955 and 1965), the overall rate of temperature increase was smaller. This is similar to the results for the Tropical Andes reported by Vuille and Bradley (2000), in which the warming rate was $0.32-0.34^{\circ} \mathrm{C}$ decade $^{-1}$ for the period of $1974-1998$ and $0.11^{\circ} \mathrm{C}$ decade $^{-1}$ for the period of 1939-1998. Our heat maps of temperature trends from different groups of stations showed that the highest warming rates were mostly in series that began after the 1960s and ended in the last available years. An exception is $T_{\min }$ during the cold season (JJA), in which there was significant warming 
(b)
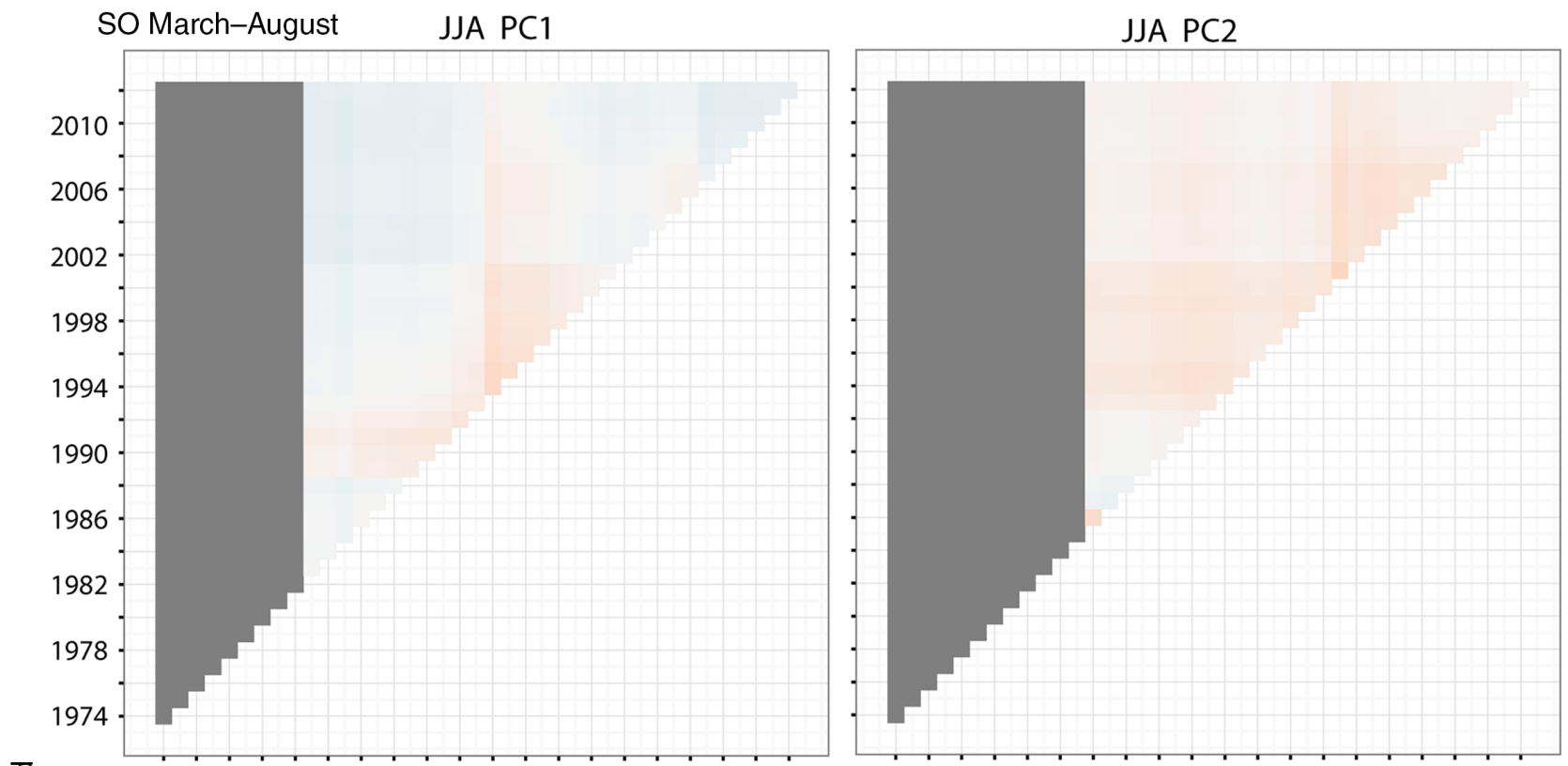

พัำ
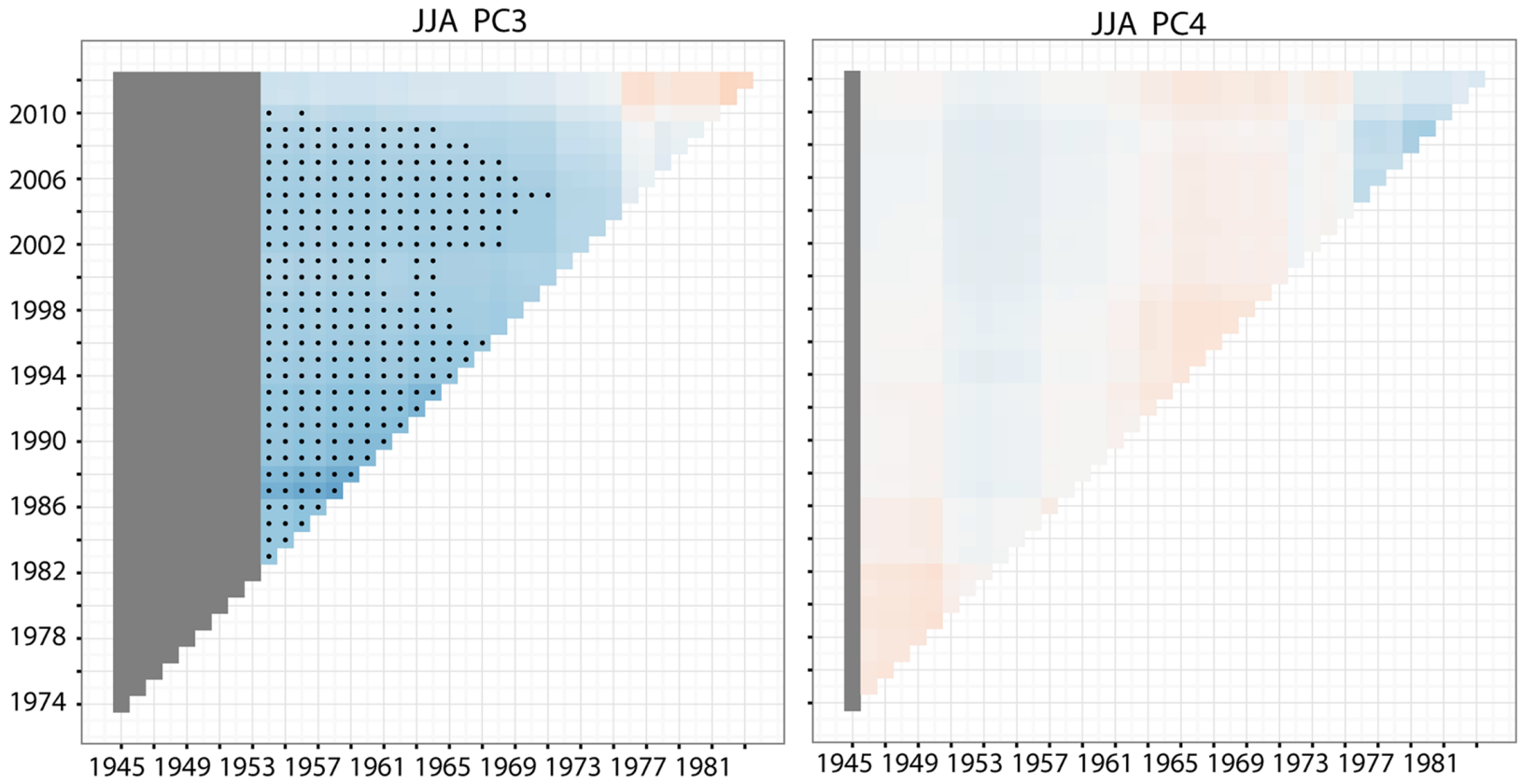

Start

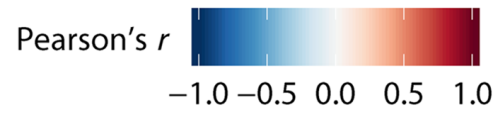

Figure 11. Continued.

at most stations for series starting around the 1950s and ending in the 1980s.

We also found that the relationship of temperature to large-scale atmospheric patterns (SO and PDO) varied for different study periods. This is in line with results obtained about the effect of the ENSO (represented by the SO in this study) in different regions of the world (López-Parages et al., 2014; Krishnaswamy et al., 2015) and other teleconnection indices (Jung et al., 2003; Vicente-Serrano and López-Moreno, 2008). PDO and SO lead to different synoptic patterns over the Andean region that strongly influences the interannual variability of temperature and precipitation (Tedeschi et al., 2013). The air temperature in Peruvian and Bolivian Andes is directly affected by SST changes in the tropical Pacific, namely temperature anomalies in the central equatorial Pacific (Niño-3 and Niño-3.4 regions) that are highly correlated with SO (Vuille et al., 2000). This is in accordance with findings by Aceituno (1988) and Rosenbluiith et al. (1997), who showed that significant positive (negative) temperature 
(c)
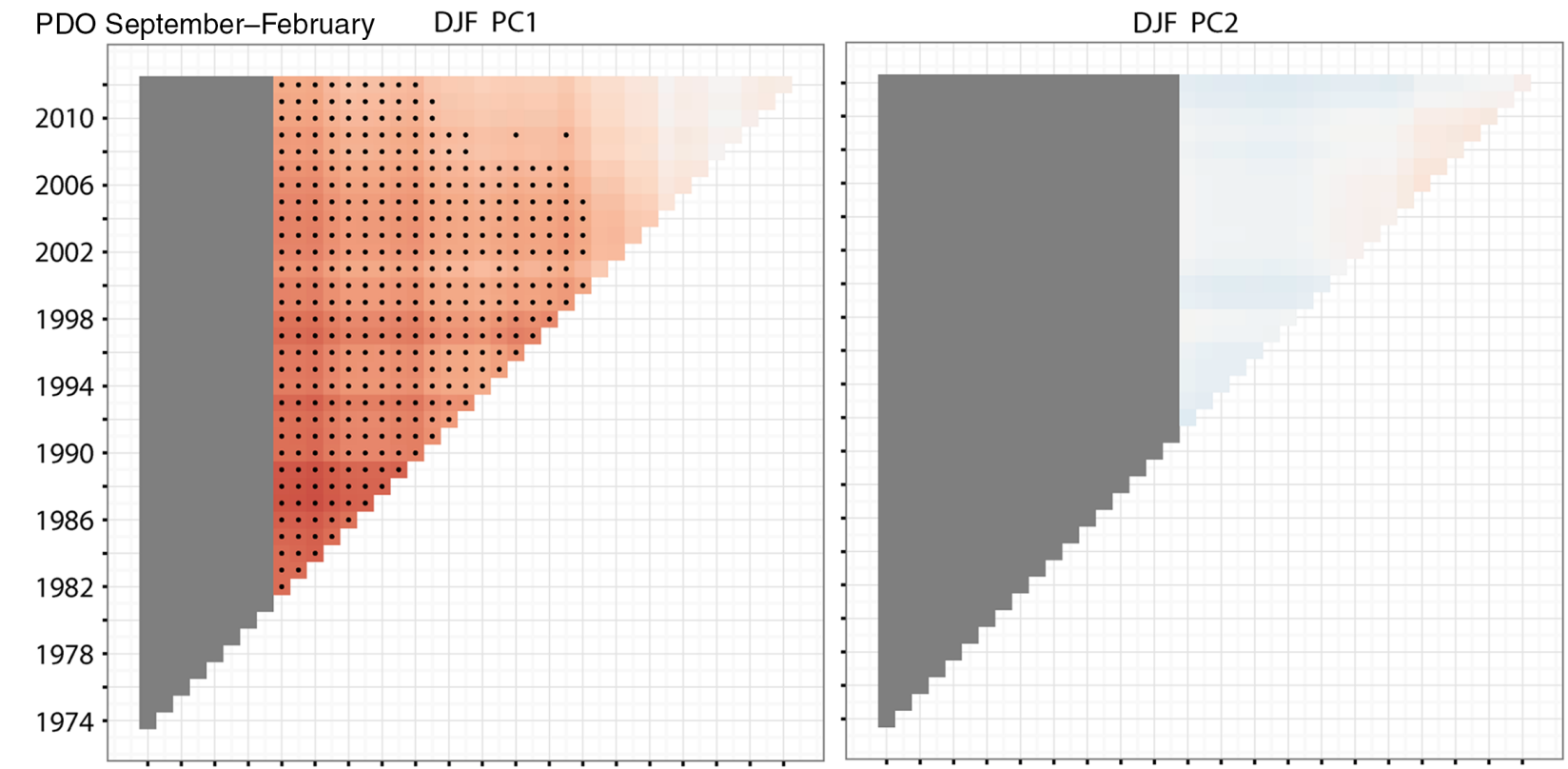

함
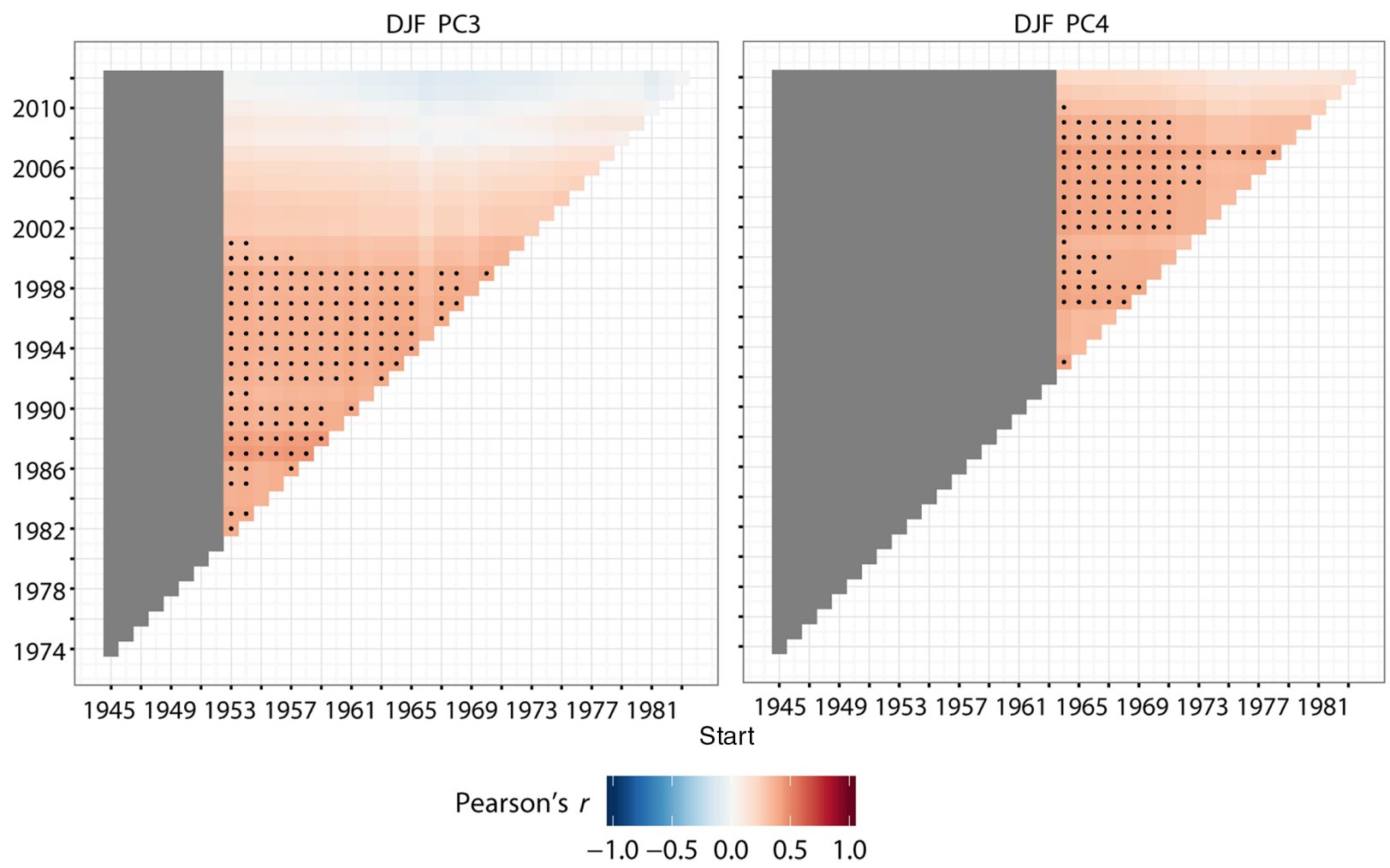

Figure 11. Continued.

departures occur at the surface and in the middle troposphere over the Altiplano and northernmost Chile during El Niño (La Niña) events. There was a mostly steady relationship between warm season $T_{\max }$ and the SO, with significant correlations for all possible combinations of starting and ending dates. This suggests that the acceleration of warming rates in recent decades does not only depend on decadal variability induced by SO. In contrast, the correlations with PDO were only statistically significant when the longest available series were analysed. The coefficients of correlation of cold season $T_{\max }$ values with the $\mathrm{SO}$ and PDO tended to increase in the most recent years at most stations; the opposite trend occurred with warm season and cold season $T_{\min }$ values, in that there were decreases in correlation at most stations when the most recent years were included in the analysis. These changes might be related with the changes in the tropical sea surface temperature in the late 1970s (Aiken et al., 2013).

Our results confirm the usefulness of the PDO and ENSO in forecasting maximum temperatures during 
(d)
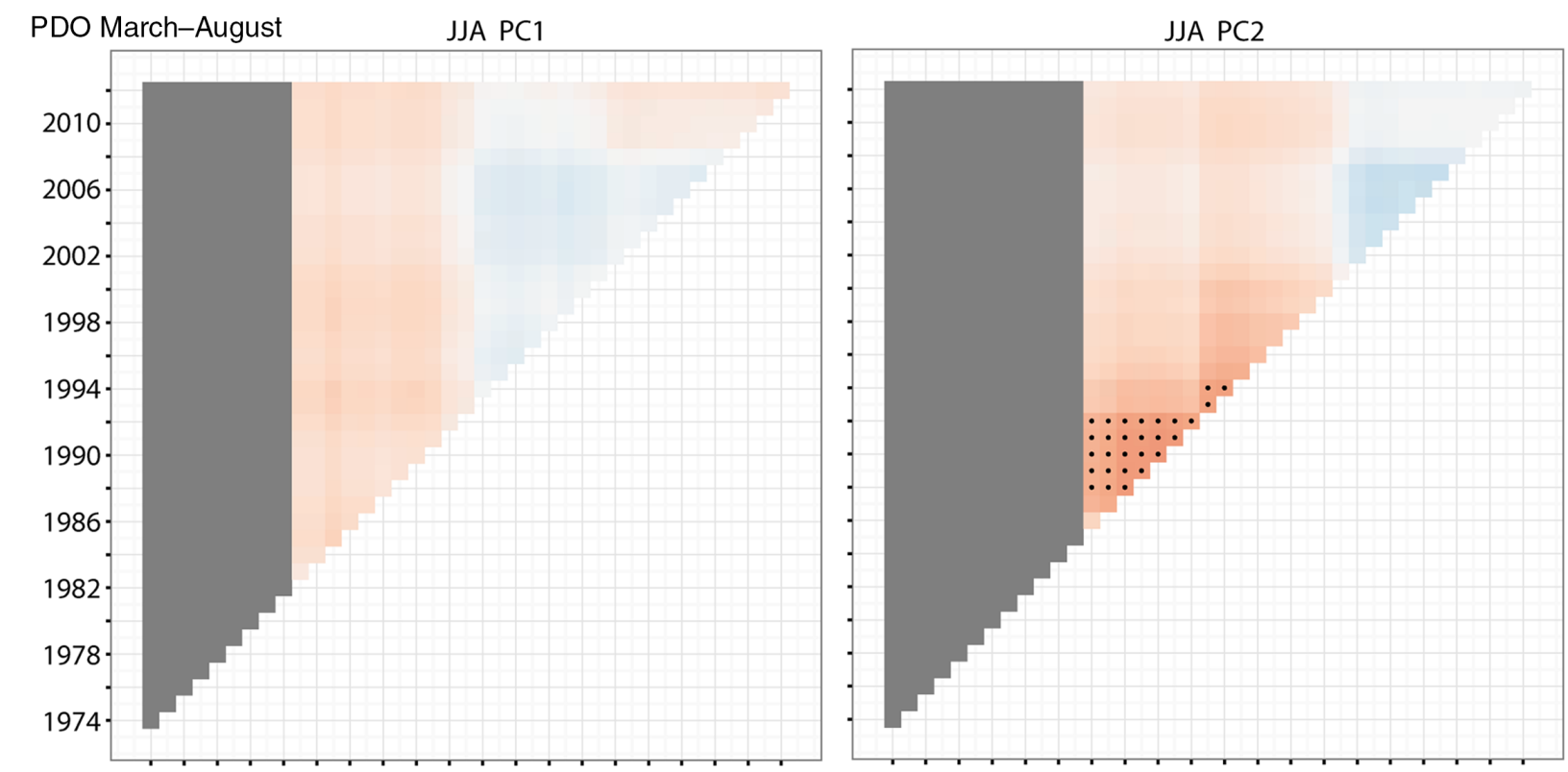

뭄
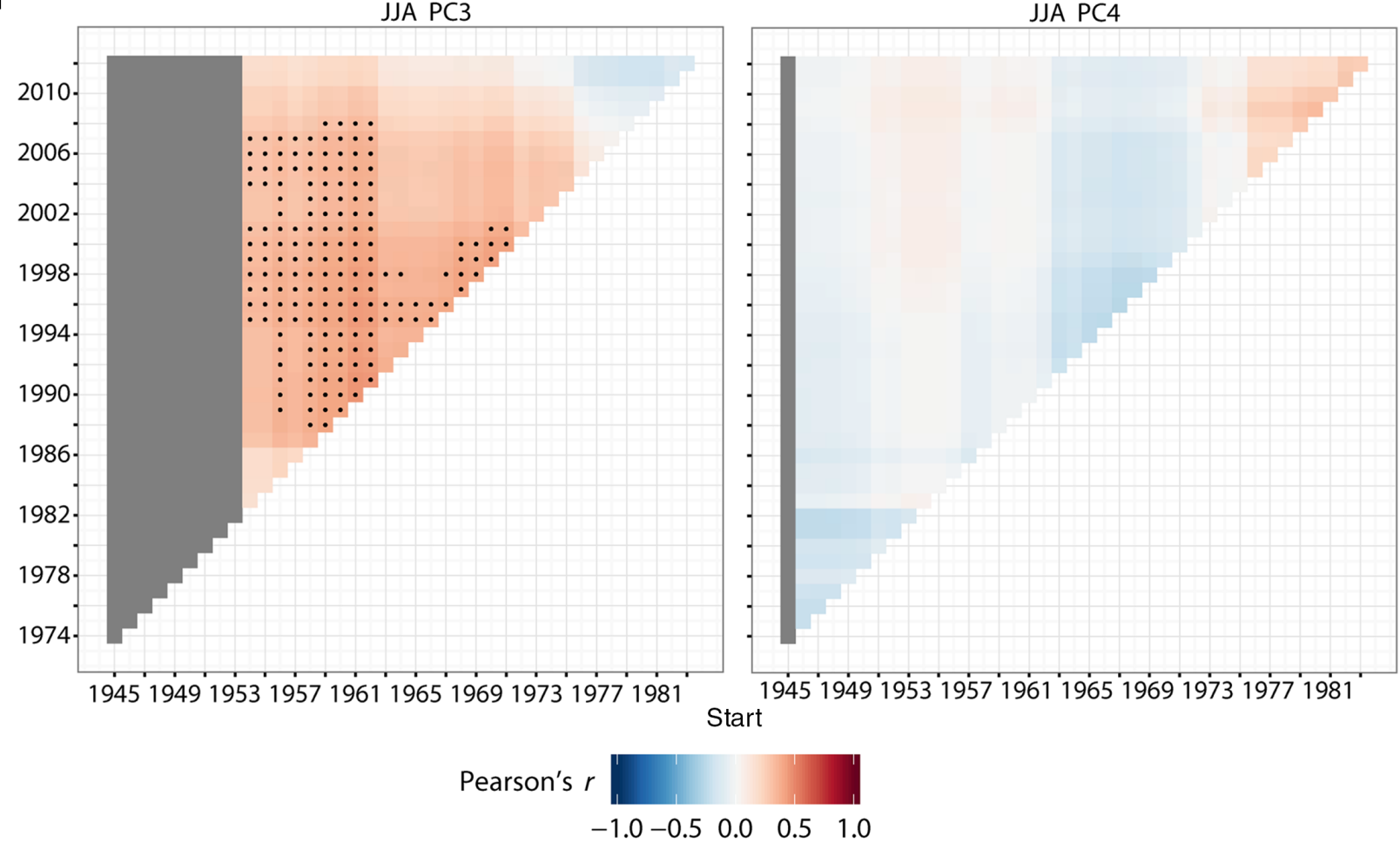

Figure 11. Continued.

the warm and cold seasons. Indeed, results stress the need for further research on the effects of ENSO on the spatio-temporal variability of temperature at different temporal scales in the Altiplano. Here, we have used an approach using the SO in line with the previous research in the region. However, the high complexity of the ENSO phenomenon is well known, and it is evidenced by the use of different SO metrics that show important differences (Niño 1+2, Niño 3, Niño 4, Niño 3 +4), and contrasted effects in different South American regions (Ashok et al., 2007; Takahashi et al., 2011). The temperature increase detected for this region is expected to continue or accelerate in the coming decades (Bradley et al., 2006; Urrutia and Vuille, 2009; Seiler et al., 2013b), and this may accelerate glacier retreat, induce changes in river regimes and reduce the availability of water resources and agricultural yields (Thibeault et al., 2010; Winters, 2012). The high vulnerability of this region to climate change (Vergara et al., 2007; Chevallier et al., 2011; Rabatel et al., 2013; Rangecroft et al., 2013) means that analysis of the potential effects of warming on this natural system and on the local population and its economy is urgently needed. 


\section{Acknowledgements}

This work was supported by the projects 'Creación de una base de datos climática de calidad para el estudio del cambio climático de las montañas del Peru-COOPB20042' and 'Test multisectorial y actividades demostrativas sobre el potencial desarrollo de sistemas de monitorización de sequías en tiempo real en la región del oeste de Sudamérica- I-COOP H2O 2013CD0006', both funded by the CSIC (Spanish Research Council). C. A-M was supported by the JCI-2011-10263 grant. A. S-L was supported as a postdoctoral fellow (2011 BP-B 00078 and JCI-201212508). Both funded by the Spanish Ministry of Economy.

\section{References}

Aceituno P. 1988. On the functioning of the Southern Oscillation in the South American sector. Part I: surface climate. Mon. Weather Rev. 116 505-524.

Aiken CM, Santoso A, McGregor S, England MH. 2013. The 1970's shift in ENSO dynamics: a linear inverse model perspective. Geophys. Res. Lett. 40(8): 1612-1617, doi: 10.1002/grl.50264.

Ashok K, Behera SK, Rao SA, Weng H, Yamagata T. 2007. El Niño Modoki and its possible teleconnection. J. Geophys. Res. 112 C11007.

Bai J. 1997. Estimating of a change point in multiple regression models. Rev. Econ. Stat. 79: 551-563.

Bai J, Perron P. 2003. Computation and analysis of multiple structural change models. J. Appl. Econ. 18: 1-22.

Battisti DS, Naylor RL. 2009. Historical warnings of future food insecurity with unprecedented seasonal heat. Science 323: 240-244.

Bradley R, Vuille M, Diaz H, Vergara W. 2006. Threats to water supplies in the tropical Andes. Science 312: 1755.

Bradley RS, Keimig FT, Diaz HF, Hardy DR. 2009. Recent changes in freezing level heights in the tropics with implications for the deglacierization of high mountain regions. Geophys. Res. Lett. 36: L17701, doi: 10.1029/2009GL037712.

Burn DH, Elnur MA. 2002. Detection of hydrologic trends and variability. J. Hydrol. 255(1-4): 107-122.

Chevallier P, Pouyaud B, Suarez W, Condom T. 2011. Climate change threats to environment in the tropical Andes: glaciers and water resources. Reg. Environ. Change 11(1): 179-187.

Francou B, Vuille M, Wagnon P, Mendoza J, Sicart JE. 2003. Tropical climate change recorded by a glacier in the central Andes during the last decades of the 20th century: Chacaltaya, Bolivia, $16^{\circ} \mathrm{S}$. J. Geophys. Res. 108(D5): 4059, doi: 10.129/2002JD002473.

Gallaire R, Taupin JD, Coudrain A. 2010. Evolution récente des paramètres cryo-climatiques et des teneurs isotopiques des précipitations dans les Andes Boliviennes: La Paz et Glacier du Zongo. J. Hydrol. Sci. 55(4): 467-483.

Garcia M, Raes D, Allen R, Herbas C. 2004. Dynamics of reference evapotranspiration in the Bolivian highlands (Altiplano). Agric. For. Meteorol. 125: 67-82.

Garcia M, Raes D, Jacobsen SE, Michel T. 2007. Agroclimatic constraints for rainfed agriculture in the Bolivian Altiplano. J. Arid Environ. $71(1)$ : $109-121$.

Garreaud RD, Battisti DS. 1999. Interannual (ENSO) and interdecadal (ENSO-like) variability in the Southern Hemisphere tropospheric circulation. J. Clim. 2: 2113-2123.

Garreaud R, Vuille M, Compagnucci R, Marengo J. 2009. Present-day South American climate. Palaeogeogr. Palaeoclimatol. Palaeoecol. 281: $180-195$.

Garrett KA, Dendy SP, Frank EE, Rouse MN, Travers SE. 2006. Climate change effects on plant disease: genomes to ecosystems. Annu. Rev. Phytopathol 44: 489-509.

Hair JFJ, Anderson RE, Tatham RL, Black WC. 1998. Multivariate data analysis. Prentice Hall: Englewood Cliffs, 730 pp.

Huth R. 2006. The effect of various methodological options on the detection of leading modes of sea level pressure variability. Tellus $A$ 58(1): $121-130$.

Jung T, Hilmer M, Ruprecht E, Kleppek S, Gulev SK, Zolina O. 2003. Characteristics of the recent eastward shift of interannual NAO variability. J. Clim. 16: $3371-3382$.
Kattel DB, Yao T. 2013. Recent temperature trends at mountain stations on the southern slope of the central Himalayas. J. Earth Syst. Sci. 122(1): 215-227.

Krishnaswamy J, Vaidyanathan S, Rajagopalan B, Bonell M, Sankaran M, Bhalla RS, Badiger S. 2015. Non-stationary and non-linear influence of ENSO and Indian Ocean Dipole on the variability of Indian monsoon rainfall and extreme rain events. Clim. Dyn. 45(1-2): $175-184$.

Lavado Casimiro WS, Labat D, Ronchail J, Espinoza JC, Guyot JL. 2013. Trends in rainfall and temperature in the Peruvian AmazonAndes basin over the last 40 years (1965-2007). Hydrol. Processes 27(20): 2944-2957.

López-Moreno JI, Fontaneda S, Bazo J, Revuelto J, Azorin-Molina C, Valero-Garcés B, Morán-Tejeda E, Vicente-Serrano SM, Zubieta R, Alejo-Cochachín J. 2014. Recent glacier retreat and climate trends in Cordillera Huaytapallana, Peru. Glob. Planet. Change 112: 1-11.

López-Parages J, Rodríguez-Fonseca B, Terray L. 2014. A mechanism for the multidecadal modulation of ENSO teleconnection with Europe. Clim. Dyn. 45: 867-880, doi: 10.1007/s00382-014-2319-x.

Magrin G, Gay García C, Cruz Choque D, Giménez JC, Moreno AR, Nagy GJ, Nobre C, Villamizar A. 2007. In Latin America Climate Change 2007: Impacts, Adaptation and Vulnerability. Contribution of Working Group II to the Fourth Assessment Report of the Intergovernmental Panel on Climate Change, Parry ML, Canziani OF, Palutikof JP, van der Linden PJ, Hanson CE (eds). Cambridge University Press: Cambridge, UK, 581 pp.

Mendoza B, Garcia-Acosta V, Velasco V, Jauregui E, Diaz-Sandoval R. 2007. Frequency and duration of historical droughts from the 16th to the 19th centuries in the Mexican Maya lands, Yucatan Peninsula. Clim. Change 83: $151-168$.

Mestre O, Domonkos P, Picard F, Auer I, Robin S, Lebarbier E, Böm R, Aguilar E. 2013. HOMER: a homogenization software - methods and applications. Q. J. Hung. Meteorol. Serv. 117: 47-67.

Picard F, Lebarbier E, Hoebke M, Rigail G, Thian B, Robin S. 2011. Joint segmentation, calling and normalization of multiple $\mathrm{CGH}$ profiles. Biostatistics 12: 413-428.

Rabatel A, Francou B, Soruco A, Gomez J, Cáceres B, Ceballos JL, Basantes R, Vuille M, Sicart JE, Huggel C, Scheel M, Lejeune Y, Arnaud Y, Collet M, Condom T, Consoli G, Favier V, Jomelli V, Galarraga R, Ginot P, Maisincho L, Mendoza J, Ménégoz M, Ramirez E, Ribstein P, Suarez W, Villacis M, Wagnon P. 2013. Current state of glaciers in the tropical Andes: a multi-century perspective on glacier evolution and climate change. Cryosphere 7: 81-102.

Rangecroft S, Harrison S, Anderson K, Magrath J, Castel AP, Pacheco P. 2013. Climate change and water resources in arid mountains: an example from the Bolivian Andes. Ambio 42: 852-863, doi: 10.1007/ s13280-013-0430-6.

Richman MB. 1986. Rotation of principal components. J. Climatol. 6: 293-335.

Rosenblüth B, Fuenzalida HA, Aceituno P. 1997. Recent temperature variations in southern South America. Int. J. Climatol. 17: $67-85$.

Schneider N, Cornuelle BD. 2005. The forcing of the Pacific Decadal Oscillation. J. Clim. 18: 4355-4373.

Seiler C, Ronald W, Hutjes A, Kabat P. 2013a. Climate variability and trends in Bolivia. J. Appl. Meteorol. Climatol. 52: 130-146.

Seiler C, Ronald W, Hutjes A, Kabat P. 2013b. Likely ranges of climate change in Bolivia. J. Appl. Meteorol. Climatol. 52: 1303-1317.

Stahl K, Moore RD, McKendry IG. 2006. The role of synopticscale circulation in the linkage between large-scale ocean-atmosphere indices and winter surface climate in British Columbia, Canada. Int. J. Climatol. 26: $541-560$.

Takahashi K, Montecinos A, Goubanova K, Dewitte B. 2011. ENSO regimes: reinterpreting the canonical and Modoki El Niño. Geophys. Res. Lett. 38: L10704.

Tedeschi RG, Cavalcanti IFA, Grimm AM. 2013. Influences of two types of ENSO on South American precipitation. Int. J. Climatol. 33: 1382-1400, doi: 10.1002/joc.3519.

Thibeault JM, Seth A, Garcia M. 2010. Changing climate in the Bolivian Altiplano: CMIP3 projections for temperature and precipitation extremes. J. Geophys. Res. 115: D08103.

Urrutia R, Vuille M. 2009. Climate change projections for the tropical Andes using a regional climate model: temperature and precipitation simulations for the end of the 21st century. J. Geophys. Res. 114: D02108, doi: 10.1029/2008JD011021.

Vergara W, Deeb A, Valencia A, Bradley R, Francou B, Zarzar A, Grünwaldt A, Haeussling S. 2007. Economic impacts of rapid glacier retreat in the Andes. Eos Trans. AGU 88(25): 261-263. 
Vicente-Serrano SM, López-Moreno JI. 2008. Nonstationary influence of the North Atlantic Oscillation on European precipitation. J. Geophys. Res. 113: D20120, doi: 10.1029/2008JD010382.

Vicente-Serrano S, Beguería S, López-Moreno JI, García-Vera MA, Stepanek P. 2010. A complete daily precipitation database for North-East Spain: reconstruction, quality control and homogeneity. Int. J. Climatol. 30(8): 1146-1163.

Vicente-Serrano SM, López-Moreno JI, Beguería S, Morán-Tejeda E, Lorenzo J, Azorín-Molina C, Gimeno L, Nieto R. 2011. A multi-scalar global evaluation of the impact of ENSO on droughts. J. Geophys. Res. 116: D16039.

Vuille M, Bradley RS. 2000. Mean annual temperature trends and their vertical structure in the tropical Andes. Geophys. Res. Lett. 27: 3885-3888.

Vuille M, Bradley RS, Keimig F. 2000. Climate variability in the Andes of Ecuador and its relation to tropical Pacific and Atlantic sea surface temperature anomalies. J. Clim. 13: 2520-2535.
Vuille M, Bradley RS, Werner M, Keimig F. 2003. 20th century climate change in the tropical Andes: observations and model results. Clim. Change 59(1-2): 75-99.

Vuille M, Francou B, Wagnon P, Juen I, Kaser G, Mark BG, Bradley RS 2008. Climate change and tropical Andean glaciers: past, present and future. Earth-Sci. Rev. 89: 79-96.

Winters C. 2012. Impact of climate change on the poor in Bolivia. Glob. Majority E J. 3: 33-43.

Yue S, Wang CY. 2002. Applicability of prewhitening to eliminate the influence of serial correlation on the Mann-Kendall test. Water Resour. Res. 38(6): 1068, doi: 10.1029/2001WR000861.

Zeileis A, Kleiber C, Krämer W, Hornik K. 2003. Testing and dating of structural changes in practice. Comput. Stat. Data Anal. 44 $109-123$.

Zhang Y, Wallace JM, Battisti S. 1997. ENSO-like interdecadal variability: 1900-1993. J. Clim. 10: 1004-1020. 